MEDEIROS, D. R. Prelúdio no 3... Villa-Lobos... processo interpretativo. Per Musi, Belo Horizonte, n.31, 2015, p.189-214.

DOI: 10.1590/permusi2015a3111

\title{
Prelúdio no 3 de Heitor Villa-Lobos: considerações sobre um processo interpretativo
}

Daniel Ribeiro Medeiros (UFPel, Pelotas, RS)

danielribeiromedeiros@gmail.com

Resumo: Este trabalho apresenta uma interpretação da peça para violão solo Prelúdio no 3, de Heitor Villa-Lobos. A análise fundamenta-se nos conceitos de performance historicamente informada (WALLS, 2002) e intuição informada (RINK, 2007). Portanto, apresenta-se aqui um estudo de caso onde a intuição e percepção musical do intérprete são reforçados por aspectos estéticos e estilísticos. Primeiramente, serão abordadas características harmônicas e de ornamentação (elementos estético-estilísticos); depois, adentra-se na análise da peça, baseada em parâmetros como plano formal, temporalidade e dinâmica (RINK, 2007), bem como de agrupamentos (JACKENDOFF; LERDAHL, 1983).

Palavras-chave: Violão; Villa-Lobos; Prelúdio no3; Análise para intérpretes.

\section{Prelúdio $n^{\circ} 3$ by Heitor Villa-Lobos: considerations on the interpretative process}

Abstract: This study presents an interpretation of the guitar solo piece Prelúdio no 3 by Brazilian composer Heitor Villa-Lobos. The analytic process is based on concepts like historically informed performance (WALLS, 2002) and informed intuition (RINK, 2007), beyond other authors. The case study presented here has the intuition and musical understanding reinforced by aesthetic and stylistic aspects. Primarily, attention is paid to harmonic and ornamental characteristics (aesthetic and stylistic elements); secondly, an analysis of the piece based on parameters such as the formal plan, temporality and dynamic (RINK, 2007), and groupings (JACKENDOFF; LERDAHL, 1983) is presented.

Key-words: Clasical Guitar; Villa-Lobos; Prelúdio nō3; Performance practice.

\section{Introdução}

O Prelúdio $n^{\circ} 3$ de Heitor Villa-Lobos faz parte da série intitulada Cinco Prelúdios, composta no ano de 1940. Segundo PRADA (2008, p.66), tal série está entre as obras para violão solo mais conhecidas do autor brasileiro. Cada Prelúdio é caracterizado extra-musicalmente em seus subtítulos ${ }^{1}$ :

- Prelúdio no 1 - Homenagem ao sertanejo brasileiro

- Prelúdio no 2 - Homenagem ao Capadócio²

- Prelúdio no 3- Homenagem a Bach

- Prelúdio $n^{\circ} 4-$ Homenagem ao índio brasileiro

- Prelúdio no $5-$ Homenagem à vida social

O fato de sua obra para violão ser muito conhecida, seja em nível nacional ou mundial, e, além disso, estar consolidada na tradição de ensino do violão como 
MEDEIROS, D. R. Prelúdio no 3... Villa-Lobos... processo interpretativo. Per Musi, Belo Horizonte, n.31, 2015, p.189-214.

repertório praticamente obrigatório na formação de todo violonista ${ }^{3}$ de concerto, é inevitável deparar-se com uma enorme quantidade de autores que a abordam.

Estabelecendo uma comparação a partir da relação simbólica entre compositores, obras e respectivos instrumentos, Turíbio Santos ${ }^{4}$ comenta: "as Baladas de Chopin são o piano. Os Prelúdios de Villa-Lobos são o violão" (Santos, citado por PRADA, 2008, p.67). DUDEQUE (1994), por sua vez, comenta que os Prelúdios "exploram de forma inteligente as possibilidades tímbricas, expressivas e técnicas do violão" (DUDEQUE, 1994, p.90), enquanto Eero TARASTI observa que os Prelúdios "incorporam todos os traços standart do estilo violonístico villalobiano, [...] movimento paralelo de acordes; ambiguidade tonal; politonalidade [...] não sistemática" (Tarasti, citado por PRADA, 2008, p.99).

Tratando da obra violonística villalobiana como um todo, Alan GOLDSPIEL observa que o compositor brasileiro combinou estilos e ritmos folclóricos brasileiros com a linguagem tonal do século $X X$, consolidando um estilo eclético e inovador (GOLDSPIEL, 2000, p.7). Ainda no que se refere às características gerais da linguagem composicional do autor brasileiro, JAFFEE (1966) destaca que o estilo de composição de Villa-Lobos:

\begin{abstract}
foi formado ecleticamente, através da combinação e observação seletiva de variadas correntes de desenvolvimento musical de seu próprio tempo e daqueles que o precederam. Sua música para violão revela forte influência de pelo menos estas fontes: Bach, Impressionismo (especialmente Debussy), a arte da miniatura instrumental (especialmente Chopin), a música de salão fin de sècle, música folclórica brasileira, e ragtime americano. Estas características emergem proeminentemente através de uma cuidadosa consideração do idioma harmônico de Villa-Lobos (JAFFEE, 1966, p.18).
\end{abstract}

Com o exposto acima, nota-se que quaisquer processos de compreensão acerca da obra para violão de Villa-Lobos (Prelúdios, Estudos, etc) coloca-nos frente a um corpus composicional multifacetado do ponto de vista estilístico. Tal estilo deve ser considerado a partir de uma perspectiva eclética, uma vez que a obra de Heitor Villa-Lobos desenvolveu-se dentro de um contexto, ou melhor, a partir dos variados contextos nos quais esteve inserido e em contato. Nota-se, portanto, que o processo de compreensão se torna uma tarefa complexa.

Não trataremos das inter-relações entre música e contextos culturais, históricos, sociais, dentre outros, uma vez que extrapolaria os limites propostos para discussão neste artigo. No entanto, sabe-se que se trata de uma parte essencial em qualquer empreitada analítica. Partiremos de elementos estilísticos que, a nosso ver, são aspectos importantes dentro da linguagem composicional da obra violonística villalobiana. É a partir deste entendimento que se propõe aqui uma abordagem que visa a construção de uma interpretação informada do Prelúdio $n^{\circ}$ 3, considerando aspectos característicos como forma de ampliação da perspectiva intuitiva do intérprete. 


\section{Considerações sobre texto, contexto e compreensão}

\subsection{Da partitura ao som (From score to sound)}

Antes de começar com as considerações analíticas mais específicas, serão apresentadas algumas observações referentes aos estágios de aprendizagem de uma obra musical. É a partir da concepção apresentada por HILL (2002), de que a partitura não é a música em si, mas sim uma série de indicações de como interpretá-la, que este trabalho fundamenta-se inicialmente:

Muitos performers se referem à partitura como 'a música'. Isso é errado, claro. As partituras registram informações musicais, algumas delas exatas, algumas delas aproximadas, junto com indicações de como essa informação pode ser interpretada. Mas a música em si é algo imaginado, primeiro pelo compositor, em seguida, em parceria com o performer, e por fim, comunicada em som (HILL, 2002, p.129).

O estágio inicial é de suma importância no processo de interpretação, uma vez que determinará o modo como tocaremos uma obra. Conforme HILL (2002, p.131), o primeiro passo está em considerar as maneiras pelas quais construímos nosso aprendizado a respeito de uma música, pois é a partir daí que começamos a "[...] estabelecer os padrões para toda obra subsequente [...]". Se nossas decisões forem "[...] tomadas rapidamente e talvez sem pensar [...] podem vir a governar como tocaremos a peça pelo resto de nossas vidas". Portanto, um posicionamento reflexivo por parte do intérprete em relação à forma como constrói seu conhecimento sobre uma obra é fundamental.

Como ponto de partida, o intérprete pode se fazer as seguintes perguntas: "que suposições estamos construindo sobre o estilo de uma peça? O que significa a notação do compositor? Qual é, de fato, nosso papel como performers em relação ao compositor?" (HILL, 2002, p.131). Pode-se considerar que a primeira pergunta está até certo ponto respondida na introdução, pelo menos de forma bem genérica ${ }^{5}$. As outras questões serão trabalhadas no tópico 3 . Características da linguagem (características harmônicas e de ornamentação) ${ }^{6}$. Dessa forma, a abordagem aqui tomada vai ao encontro da ideia de que a interpretação é, essencialmente, "a arte de ler as entrelinhas" (HILL, 2002, p.131). É no espaço correspondente às entrelinhas que a nosso ver se estabelece o próprio processo hermenêutico, ou seja, é no diálogo entre interlocutor (intérprete) e texto que se constrói a aprendizagem e a compreensão musical.

\subsection{Peformance Historicamente Informada (Historically Informed Performance)}

WALLS (2002) apresenta uma discussão em torno do conceito de performance historicamente informada (historically informed performance). Em linhas gerais, uma vez que o intérprete decide compreender uma determinada obra, deve observar a partitura como um texto que, de uma forma ou outra, registra uma 
linguagem composicional carregada de pressupostos estéticos, culturais, etc. A perspectiva histórica apresenta-se, por exemplo, na medida em que o intérprete considera elementos do estilo composicional dentro da(s) perspectiva(s) de normas e convenções estéticas com as quais o compositor teve contato (seja através do contato da obra de outros compositores, analisando-as, ouvindo-as, etc; seja através de instruções formais, como por exemplo, ter tido aulas em conservatórios ou outras instituições de ensino musical; etc. Ou seja, através dos mais variados processos de imersão no meio cultural). Dessa forma, pode-se entender sua obra como uma espécie de reelaboração destas convenções, uma vez que o mesmo acaba por adaptá-las às suas necessidades artísticas e expressivas.

Embora o autor apresente exemplos de como estabelecer uma leitura contextualizada a partir das características estilísticas relacionadas a determinados parâmetros na obra de um determinado compositor ${ }^{7}$, destaca que tal leitura não pode substituir o papel participativo do performer. Conforme WALLS (2002, p.23), as respostas certas sobre as características estilísticas referentes à notação, por exemplo, nem sempre são fáceis de serem obtidas, quando não são impossíveis. Além disso, tais respostas não devem ser consideradas como substitutas da imaginação do performer:

$\mathrm{Na}$ melhor das hipóteses, o terreno dentro do qual a imaginação funciona é aquele em que um conjunto de hipóteses recebidas é deslocado por uma gama alternativa de possibilidades estilísticas. Esse processo de deslocamento pode mesmo atuar como um estímulo à imaginação musical (WALLS, 2002, p.23).

O intérprete, portanto, possui um papel fundamental no processo de levar ao público uma mensagem musical que reflita um diálogo entre as concepções artísticas do compositor e as suas próprias:

O performer, cuja tarefa é a de tornar real a partitura para as audiências contemporâneas, está especialmente preocupado com este ato de mediação entre um passado histórico e um presente estético (WALLS, 2002, p.24).

Sendo assim, o intérprete, no processo de assimilação de determinada obra, pode trazer à tona as possíveis concepções do compositor enquanto um ser humano que estava imerso em uma determinada época, com seus padrões estéticos, culturais, históricos, dentre outros. Estabelece-se assim, a ideia da obra como um artefato que é trazido do passado para ser refletido no presente. Na medida em que o intérprete aprofunda tal processo, vai se constituindo um diálogo, onde valores de épocas distintas vão se fundindo. É nesta fusão reflexiva, portanto, que o intérprete acaba por imprimir suas concepções a respeito da obra, como uma espécie de re-composição. Para isso, o entendimento de elementos e a busca de informações sobre parâmetros característicos à época passada se torna uma ferramenta imprescindível na construção de uma concepção interpretativa fundamentada. 


\section{Características da linguagem}

\subsection{Características harmônicas}

JAFFEE (1966) observa que à primeira vista as composições (Prelúdios, Estudos, etc) para violão de Villa-Lobos parecem apresentar estruturas harmônicas politonais. Tais análises ocorrem pelo fato de que em muitos trechos as definições de tonalidades ou centros tonais se tornam nebulosas, permitindo uma série de interpretações neste sentido. No entanto, através de uma observação mais detalhada, tais estruturas se tornam meras ocorrências focais, não se constituindo como elementos sistemáticos. Portanto, uma politonalidade estrita não é encontrada na obra para violão solo de Villa-Lobos. Há "claramente a supremacia de um centro tonal" (JAFFEE, 1966, p.20). Um exemplo deste aspecto pode ser observado já nos c.1-3 do Prelúdio no 3 (Ex.1):

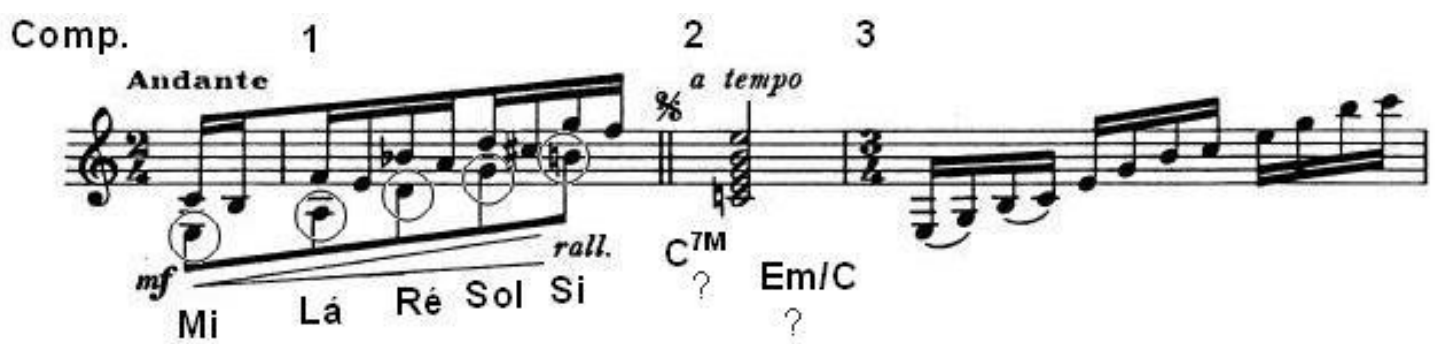

Ex.1 - Ocorrência focal de "falsa" politonalidade no Prelúdio $n^{\circ} 3$ (c.1-3) de Villa-Lobos devido a utilização das características da afinação do instrumento como participantes do material musical

(Mi, Lá, Ré Sol e Si nas colcheias correspondem à afinação natural do violão - c.1).

Conforme JAFFEE (1966) a passagem em que as semicolcheias movem-se contra as colcheias confere um grau de incerteza harmônica que acaba "resolvendo" no acorde de Dó maior com sétima maior - ou um acorde de Mi menor com sexta no baixo? (c.2). Nos c.6-7, ocorre uma passagem similar (Ex.2) que, por sua vez, transpõe a mesma figuração motívica do Ex.1, "resolvendo" no acorde de Fá\# maior (c.7):

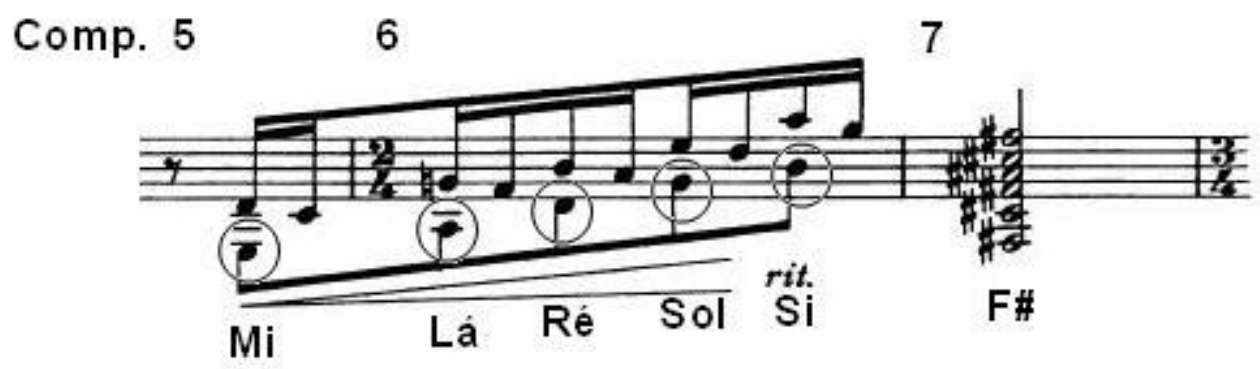

Ex.2 - Outro exemplo de ocorrência focal de "falsa" politonalidade no Prelúdio no 3 (c.6-7) de VillaLobos. Mais uma vez o compositor utiliza a característica da afinação do instrumento como material musical. 
Tal caráter pode ser compreendido através da íntima relação entre os materiais musicais e o idioma do instrumento. A exploração que Villa-Lobos desenvolveu sobre este aspecto, acarretou em uma série de inovações musicais e técnicas para o violão. Segundo GOLDSPIEL (2000, p.7), "o uso do violão em Villa-Lobos torna-se uma parte integral da estrutura musical, e suas técnicas nunca são aplicadas de forma aleatória“. O uso extensivo de movimentação paralela entre acordes (plantings), arpejos (arpeggiation) e acordes onde as cordas soltas funcionam como notas pedais (open string pedal tones) são muito recorrentes e possuem importantes funções estruturais. Muitas vezes as cordas soltas funcionam como pedais que, juntamente com outros elementos, reiteram um único centro tonal (GOLDSPIEL, 2000, p.8). Nos c.1-4 do Estudo $n^{\circ} 11$ (Ex.3), por exemplo, tem-se uma amostra dos acordes com notas pedais soltas (open string pedal notes):

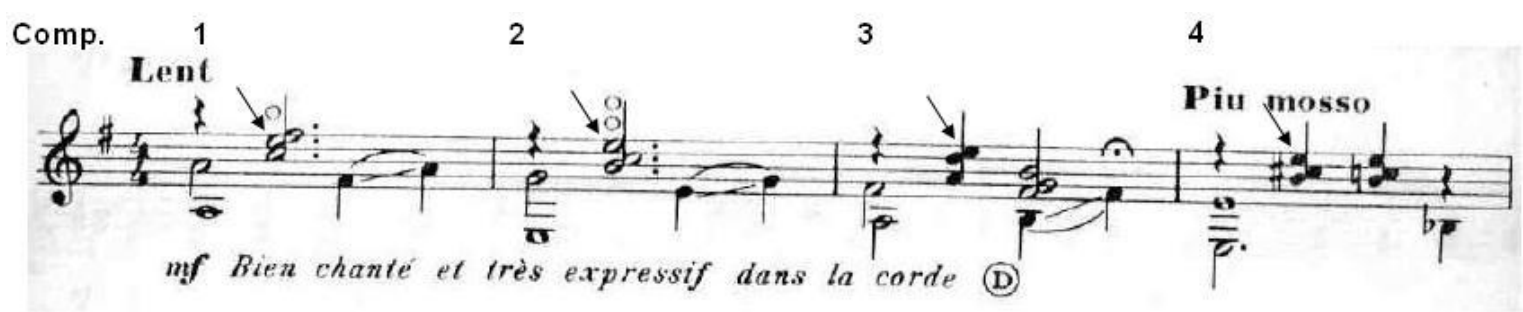

Ex.3 - Exemplo de open string pedal tone (marcadas com as setas) com a nota Mi (corda solta) no Estudo no 11 de Heitor Villa-Lobos (c.1-4).

Para GOLDSPIEL (2000, p.8), Villa-Lobos claramente encontrou nestas formações um dispositivo composicional atrativo que permite um reforço nos legatos (as notas soltas geram essa sensação), conexões harmônicas distintas, dissonâncias, e variedade de cor. Ainda observa que o compositor brasileiro utilizou em muitas obras tríades, acordes de sétima diminuta ou de sétima da dominante movimentando-se de forma paralela (paralelism), ou seja, sem mudança na formação dos acordes através do braço do violão (fingerboard). Um exemplo deste recurso está no Estudo no 12 (Ex.4):

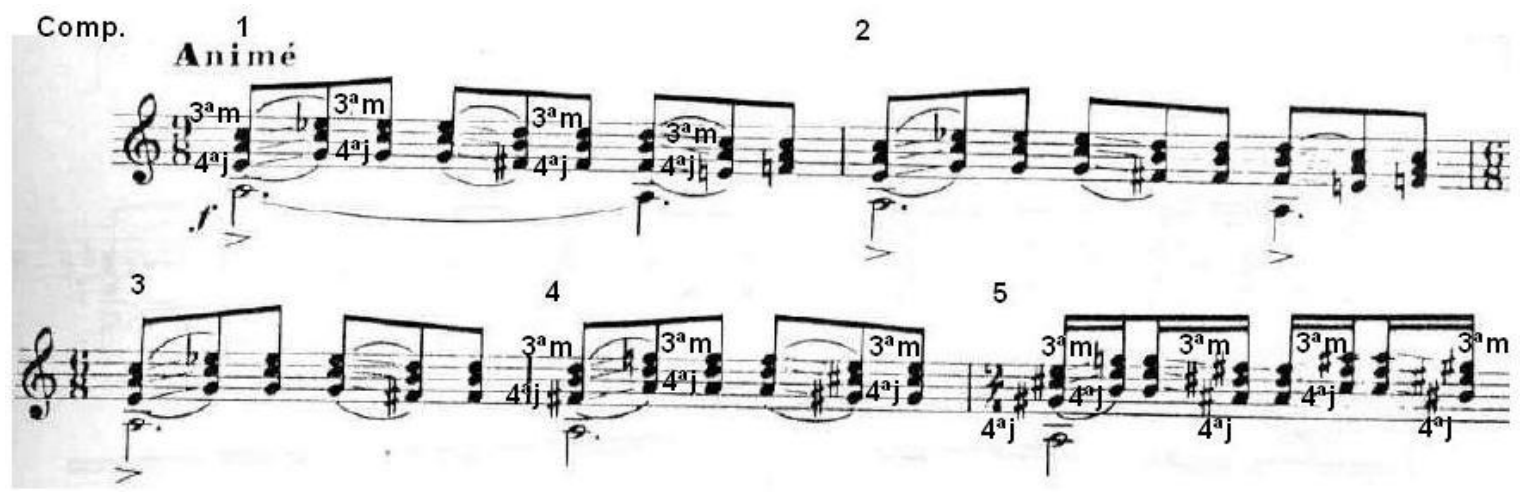

Ex.4 - Trecho inicial do Estudo no 12 (c.1-5) de Heitor Villa-Lobos onde a movimentação paralela (paralelism) de uma mesma formação de acorde (acorde menor em segunda inversão) atua sobre o pedal em Lá. 
Neste tipo de contexto, os acordes não possuem funções tonais tradicionais. Para Villa-Lobos, estes acordes proporcionavam possibilidades colorísticas e de variação (GOLDSPIEL, 2000, p.8), remetendo à utilização de elementos harmônicos através de uma perspectiva impressionista.

O Ex.5 corresponde ao trecho da Seção A do Prelúdio no 3 (c.9-13), onde ocorrem movimentações paralelas de acordes com as mesmas estruturas:
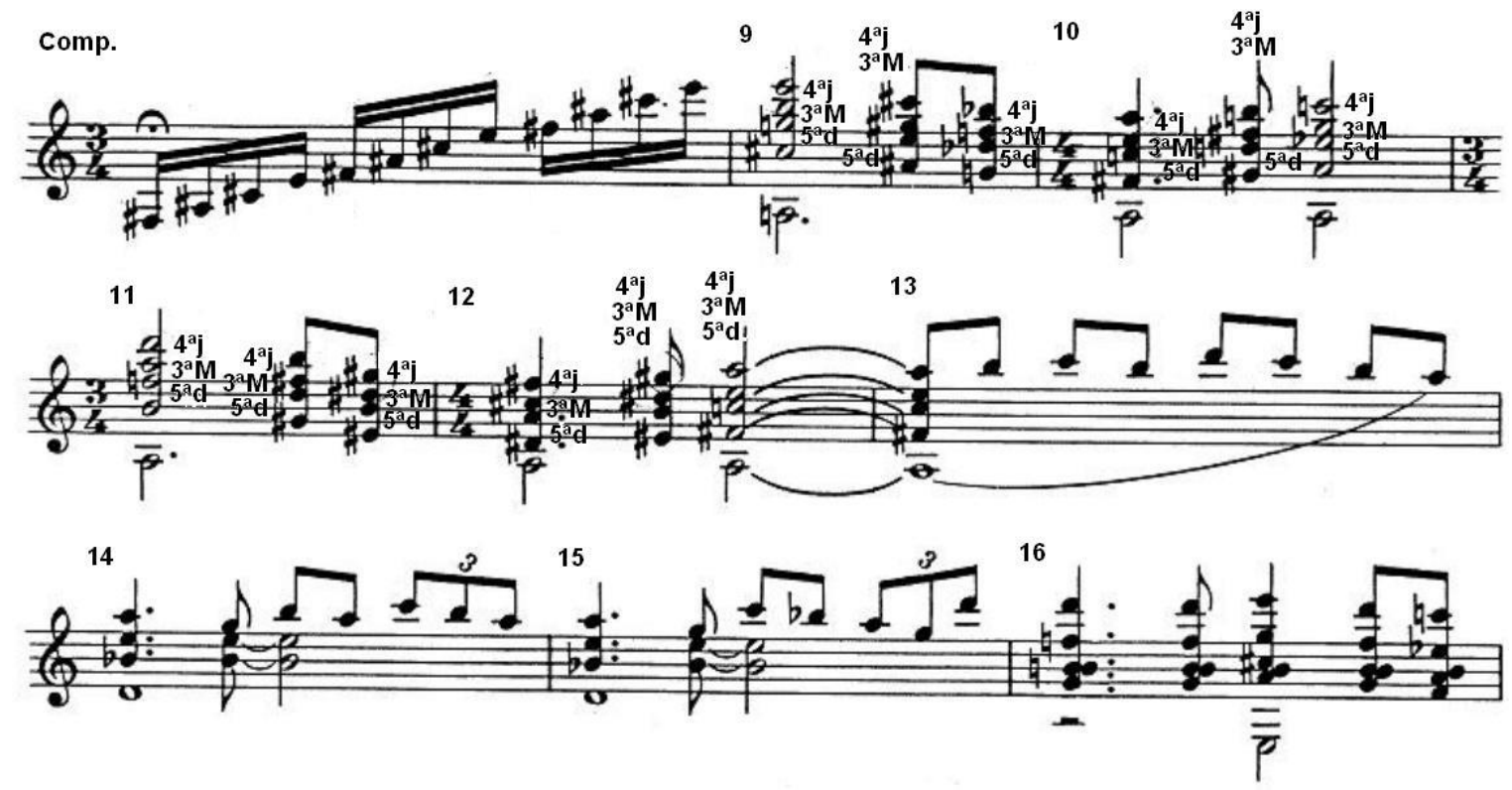

Ex.5 - Trecho do Prelúdio nํㅜ (c.9-13) de Villa-Lobos onde ocorre paralelismo (paralelism).

\subsection{Ornamentação}

Turíbio Santos traça algumas considerações a respeito do Prelúdio no 3 em Heitor Villa-Lobos e o violão (1975). Suas colocações podem ser tomadas como bases para uma interpretação da obra violonística de Villa-Lobos pelo fato de ter trabalhado juntamente com o compositor brasileiro. No contexto da obra para violão solo de Villa-Lobos, SANTOS (1975) observa alguns problemas interpretativos. Segundo ele

a exuberância da música para violão de Villa-Lobos pode enganar o executante, causando uma interpretação excessivamente indefinida, com rubatos prolongados, uma impetuosidade exagerada e um excesso do abuso temperamental do estilo (SANTOS, 1975, p.40).

Na Seção B há uma indicação ornamental que, na visão de SANTOS (1975), confunde muitos violonistas que não estão informados quanto à sua compreensão. Trata-se do portamento 8 (Ex.6): 
Comp. 23

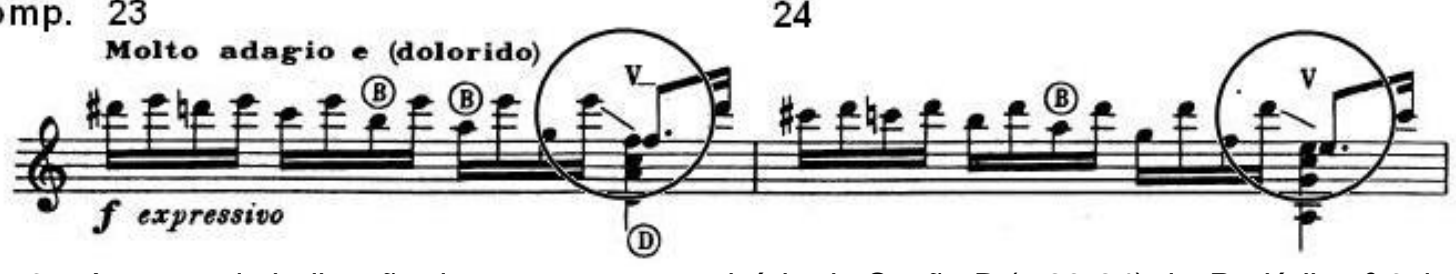

Ex.6 - Amostra da indicação de portamentos no início da Seção B (c.23-24) do Prelúdio no 3 de Villa-Lobos. Recorrente em toda a seção.

Tal ornamento refere-se a um escorregar (slur) do dedo de forma descontínua entre as notas indicadas. Ou seja, o escorregar (slur) "dilui" o movimento sonoro ao longo do movimento do dedo, não devendo ser interpretados como um glissando propriamente dito (terminando de forma clara na nota de chegada). Além disso, o intérprete deve decidir como tocar este portamento a fim de não produzir uma sonoridade indesejada para o trecho (SANTOS, 1975, p.33).

O autor, ainda menciona um dos problemas que estão entre os grandes desafios de todo violonista que defronta-se com qualquer peça do repertório villalobiano: os sons estranhos e considerados desagradáveis que ocorrem durante a execução de glissandos e/ou portamentos nas cordas graves do instrumento. Estes se configuram como um dos problemas mais frequentes com o qual os intérpretes se deparam. Dessa forma, "alguns violonistas solucionam o problema pela omissão deliberada de glissandos e portamentos" (SANTOS, 1975, p.41). É importante salientar que estes ornamentos se configuram como elementos de estilo, ou seja, são elementos estéticos manifestos na obra do compositor. Dessa maneira, não podem ser desconsiderados de forma arbitrária por parte do intérprete.

\section{Prelúdio nº 3: uma análise}

\subsection{Plano formal}

A importância do plano formal está em proporcionar a compreensão do molde no qual a obra está organizada. Segundo RINK (2007),

\footnotetext{
tais modelos com a forma binária e ternária, rondó, etc, são familiares para a maioria dos músicos, e analisar uma obra nestes termos logo no começo pode ser produtivo, seguindo-se talvez um delinear mais detalhado, individual, revelando as principais sessões ou subseções da música, plano tonal e outros aspectos relevantes (RINK, 2007, p.35).
}

O Prelúdio no 3 de Villa-Lobos organiza-se através da forma binária A-B. A Seção A não fecha-se em si mesma, seja do ponto de vista de sua estrutura harmônica, seja através de outros elementos. É estabelecida uma conexão com a Seção B através de um discurso que não é interrompido (Ex.7): 


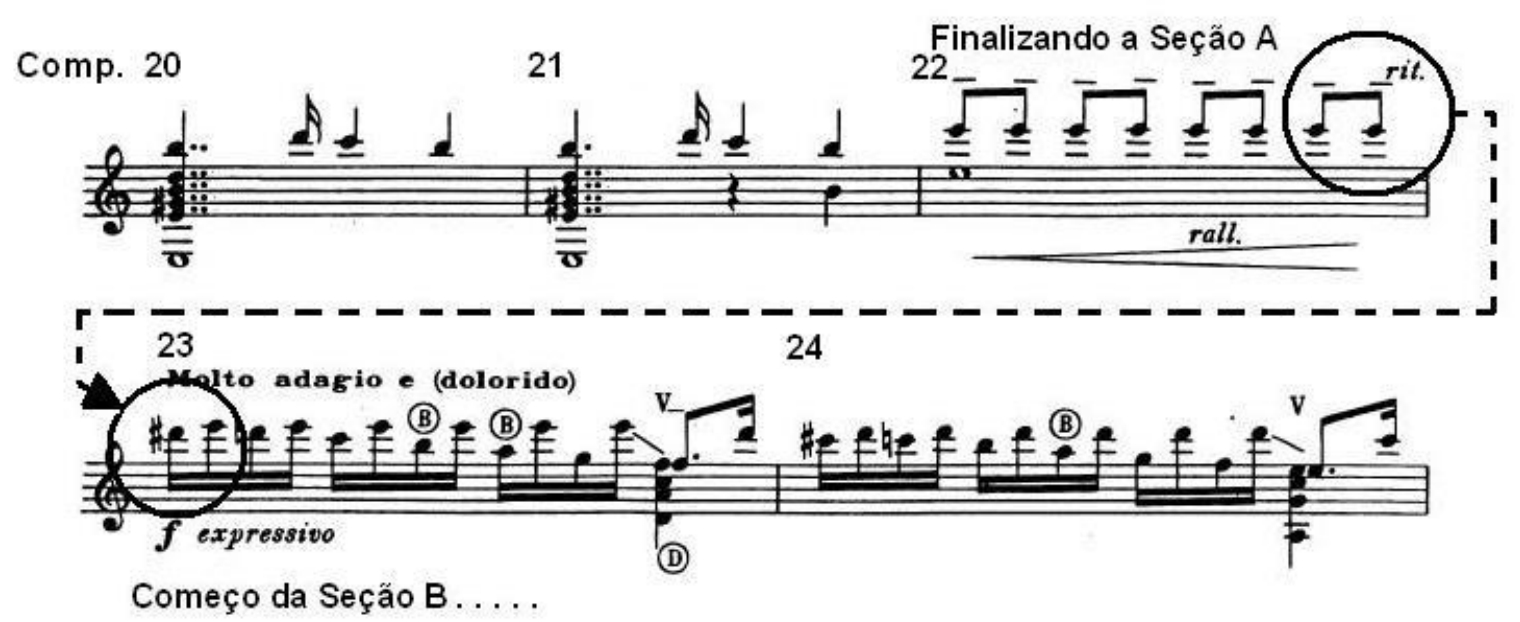

Ex.7- Transição entre as Seções A e B (c.20-24) do Prelúdio nº 3. Fluxo do discurso musical não é interrompido.

Nota-se que no c.22 não há nenhuma referência de quebra do fluxo do discurso musical como barra dupla, cesura, etc. No entanto, as indicações de ralentando (rall), ritenuto (rit), aumento da dinâmica (abaixo do pentagrama) e os tenutos chamam atenção quando observadas de forma inter-relacionada. A quantidade de informações que oferecem reforça o segmento como uma transição da Seção $A$ para a Seção B. O rall. sugere a diminuição agógica a partir do terceiro tempo do compasso; os tenutos indicam que as notas agudas devem ter suas durações estendidas, bem como dissolver a métrica ${ }^{9}$; a indicação de crescendo reforça a expectativa de que uma nova anacruse (upbeat) ${ }^{10}$ está por vir; e o rit. sobre a última Mi4 ${ }^{11}$, pode ser interpretado como uma indicação de que tal nota não corresponde mais ao contexto da Seção A, mas sim, como anacruse (upbeat) da Seção B. A decisão de tomar o último Mi do c.22 como anacruse (upbeat) justifica-se pelo modo como cada uma das frases da Seção B (melodias polifônicas ao estilo de Bach) estão agrupadas (Ex.8): 
Comp. 23

24
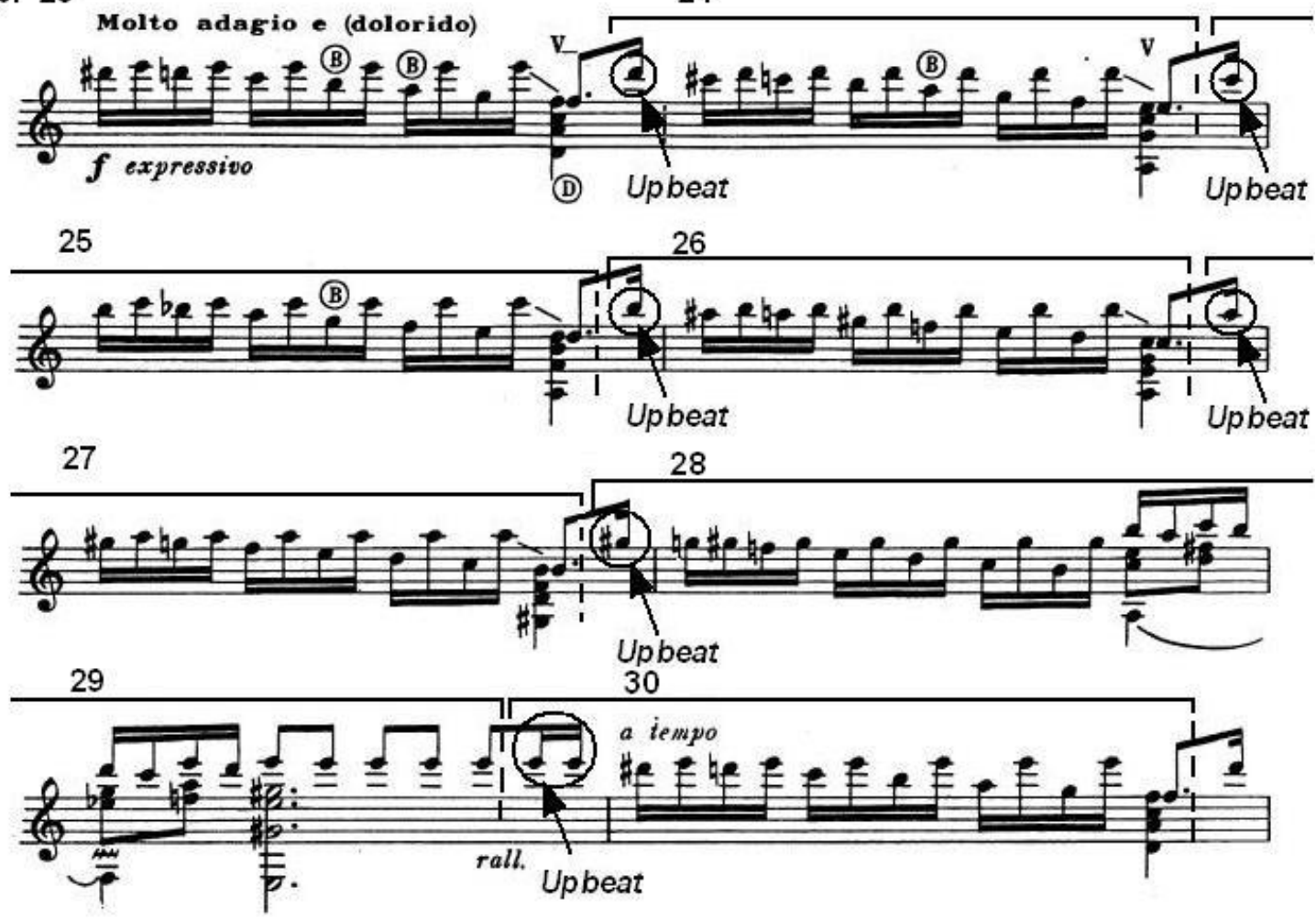

Ex.8 - Agrupamentos (groupings) frasais na Seção B como elementos que justificam a decisão sobre a anacruse (upbeat) no c.22.

Portanto, a partir dessa concepção, pode-se pensar o trecho da seguinte maneira (Ex.9):

Comp. 20

21
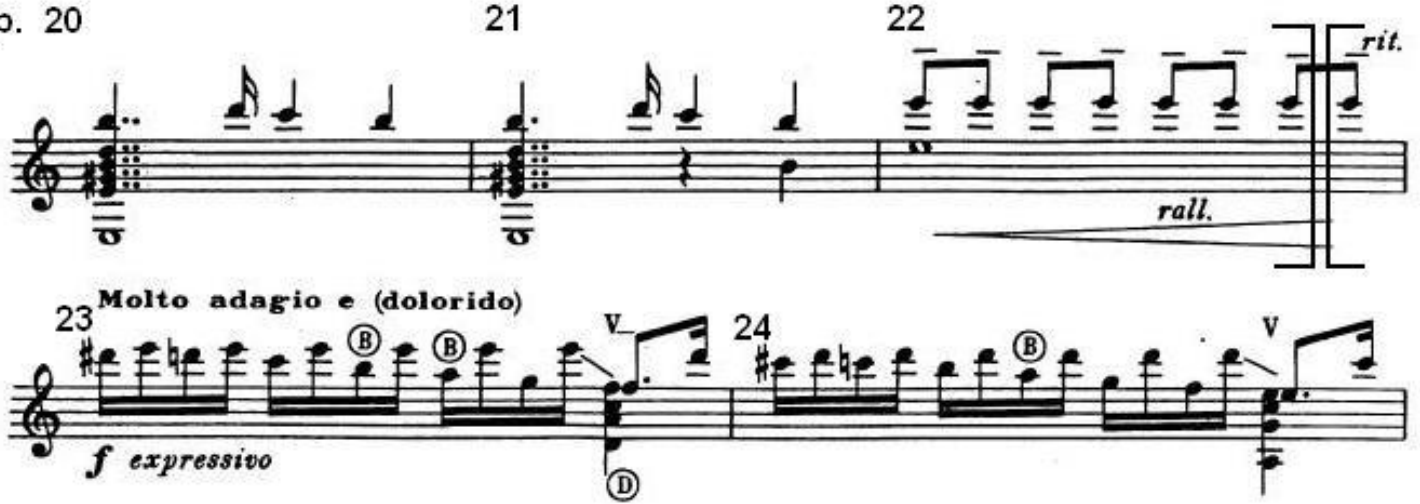

Ex.9 - Definição do ponto onde termina a Seção A e começa a Seção B do Prelúdio no 3 (c.20-24) de Villa-Lobos.

O processo harmônico também reforça a concepção de que o segmento discutido acima se caracteriza como transição entre Seções. Nota-se que a Seção A, que vai do início da peça até o c.22, apresenta um caráter incerto, uma vez que as relações harmônicas tonais são obscurecidas pela utilização de muitos acordes de 
sétima da dominante, assim como "resoluções" inesperadas. Porém, a relação tonal de movimento está implícita e pode ser percebida pelo intérprete. A tônica Lá menor (i) é estabelecida somente no final da peça. A chegada até este acorde ocorre somente após a concepção de um "grande retardo".

Ao final da Seção $A$ chega-se ao $\mathrm{V}^{7}$ (dominante da tonalidade de Lá menor), reforçando o caráter transitório dos c.20-22 através de uma divisão estrutural do ponto de vista harmônico (Ex.10):

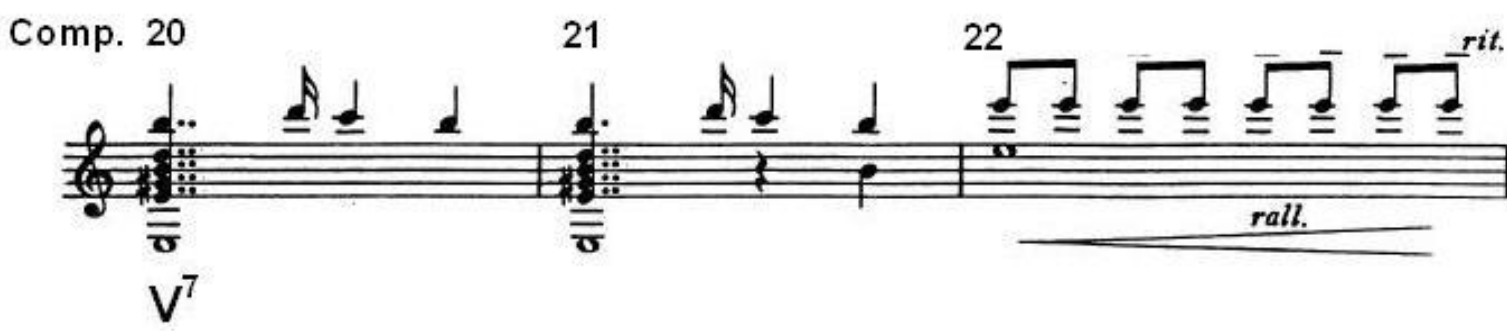

Ex.10 - Trecho (c.20-22) onde se estabelece o $\mathrm{V}^{7}$ estrutural que reitera o ponto de transição entre as Seções A e B do Prelúdio no 3.

Trata-se de uma forma A-B que possui uma movimentação harmônica única dentro da combinação das partes (Continuous binary form), não rompendo com o fluxo do discurso musical no que se refere às considerações do parâmetro harmônico (GREEN, 1979, p.74-75): sem modulações à outras regiões, nem chegada ao i (tônica). Pode-se entender, portanto, que a Seção A apresenta uma espécie de movimento que visa atingir um ápice. No c.20 é alcançado o $V^{7}$, estabelecendo um momento de instabilidade tonal, expectativa, tensão estrutural. Após este momento, o ápice tonal começa a ser dissipado na Seção B através de um movimento claramente direcionado à tônica (Lá menor).

Portanto, o plano formal pode ser pensado da seguinte maneira (Ex.11):

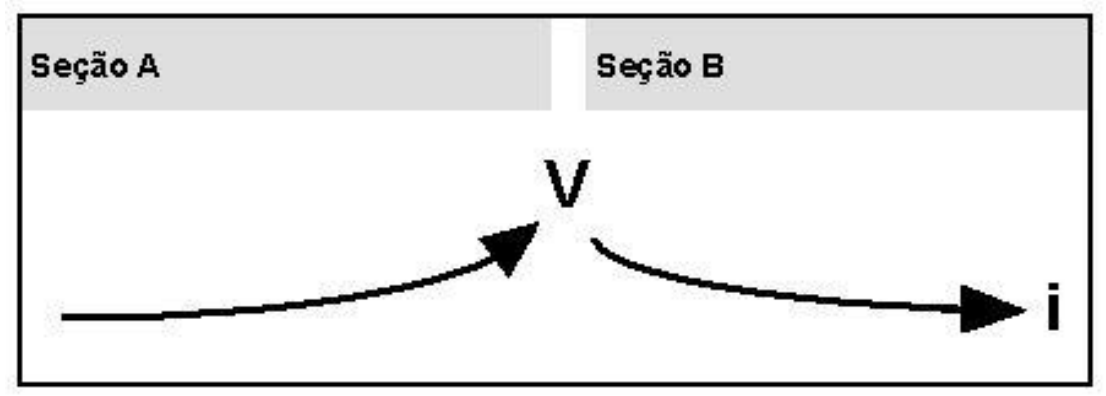

Ex.11 - Visualização do plano formal geral do Prelúdio nº 3 de Villa-Lobos. 


\subsection{Gráfico de Tempo}

Segundo RINK (2007), embora este tipo de gráfico possa fornecer uma

ideia valiosa da flutuação do tempo na execução, intérpretes e ouvintes são incapazes de perceber estas nuances no sentido literal: os 'fatos' brutos da performance demonstrados por estes dados revelam uma verdade parcial e por vezes enganosa (RINK, 2007, p.36).

Apesar da consideração que o autor faz em relação à incapacidade de intérpretes e ouvintes na percepção de nuances temporais, pretende-se construir este tipo de gráfico no intuito de mapear o contorno da temporalidade da peça.

Villa-Lobos faz uso razoável de indicações agógicas, conferindo um caráter temporal mais "livre", "flutuante". A Seção A indica o andamento Andante (Ex.12), e a Seção B estabelece um contraste através da indicação de Molto adagio (dolorido) (Ex.13):

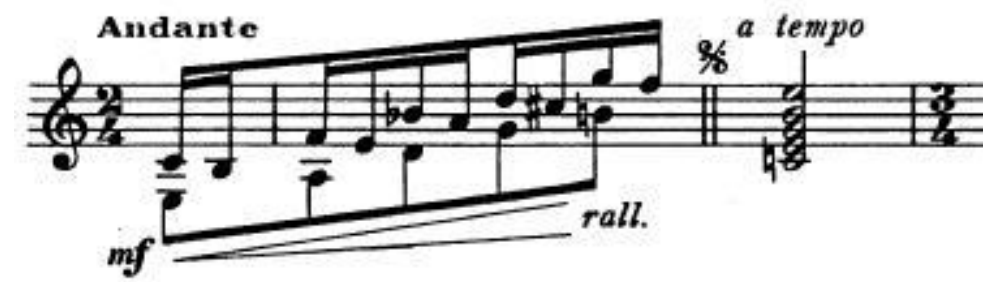

Ex.12 - Indicação de tempo (andante) no início da Seção A (c.1-2) do Prelúdio no 3 de Villa-Lobos.

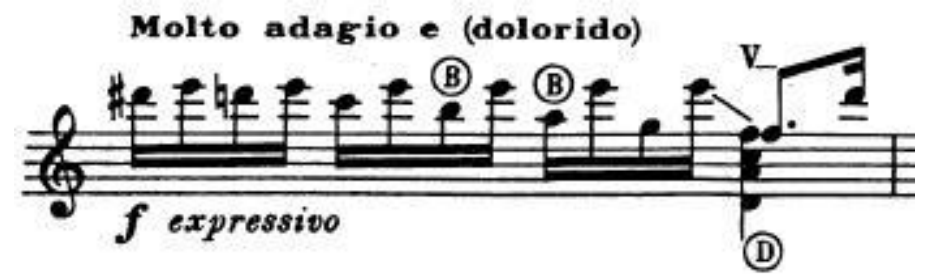

Ex.13 - Indicação de tempo (molto adagio) no início da Seção B (c.23) do Prelúdio no 3 de VillaLobos.

Referente ao fato de que a peça não apresenta indicação metronômica, será considerado que há mudança de um andamento médio (Andante) para um andamento lento (Molto adagio) (Ex.14): 


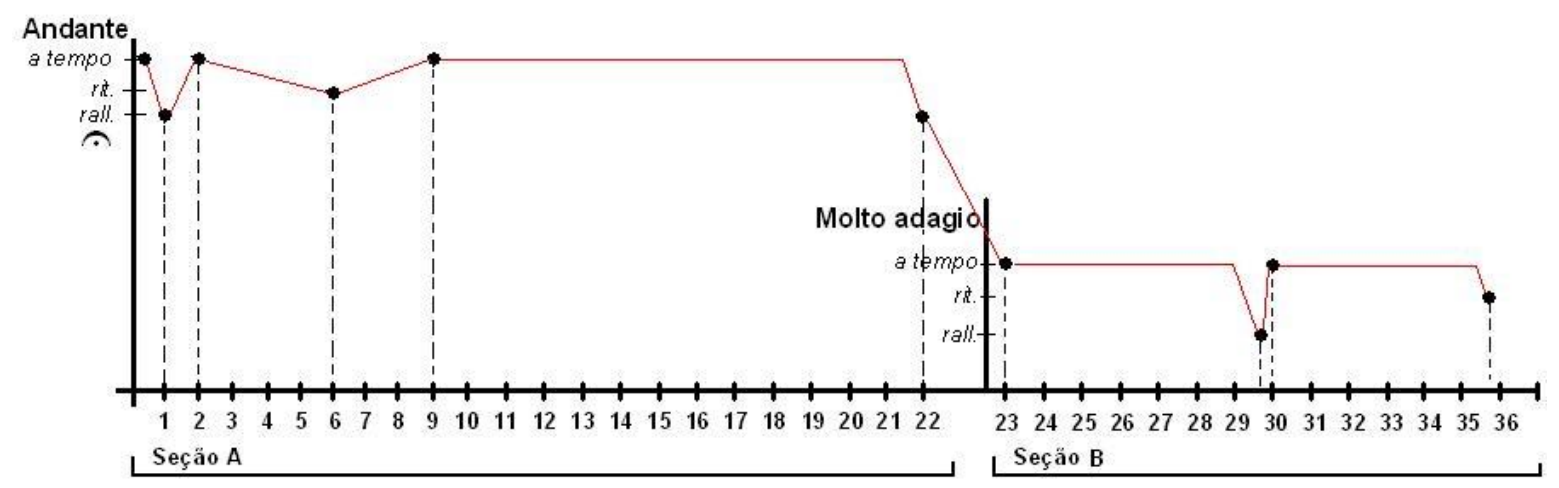

Ex.14 - Gráfico de flutuação do tempo no Prelúdio $n^{\circ} 3$ de Villa-Lobos. Eixo vertical indica a variabilidade temporal; o eixo horizontal indica os compassos.

É importante ressaltar, após a observação do gráfico acima, que tanto a visão panorâmica do contexto harmônico como o gráfico de flutuação do tempo, pode-se pensar em um caráter descendente, ou seja, um movimento que se dirige, nos dois parâmetros, para um repouso ao final da peça. Mais um ponto deve ser considerado: no gráfico, a indicação de rall. é colocada abaixo do rit.. Isso se deve ao fato de que uma possui carga temporal mais ampla que a outra respectivamente.

\subsection{Gráfico de dinâmica}

Há uma grande economia de indicações de dinâmica na peça, o que pode abrir para o intérprete a possibilidade de maior criação de nuances de intensidade sonora. Os sinais ocorrem em pontos estruturais da peça, ou seja, o $m f$ ocorre no início da Seção A (Ex.15), o $f$ ocorre no início da Seção B (Ex.16), e o $p$ ocorre ao final (Ex.17):

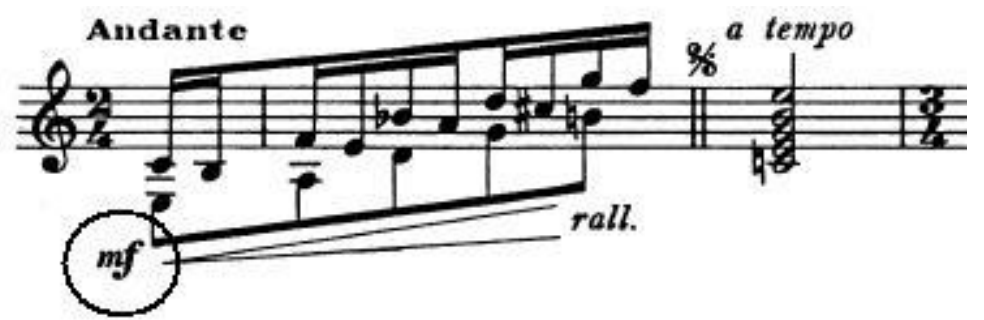

Ex.15 - Indicação de dinâmica $(m f)$ no início da Seção A (c.1-2) do Prelúdio no 3 de Villa-Lobos.

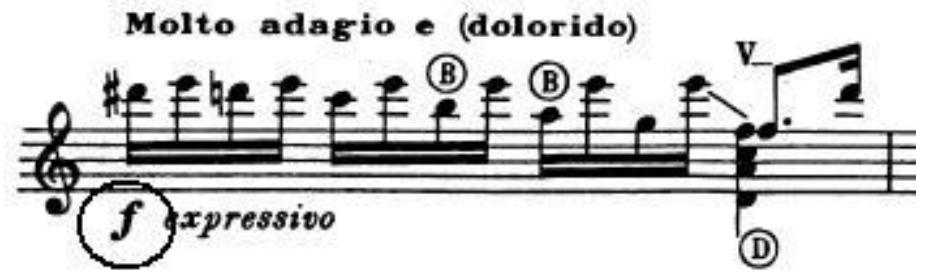

Ex.16 - Indicação de dinâmica $(f)$ no início da Seção B (c.23) do Prelúdio no 3 de Villa-Lobos. 


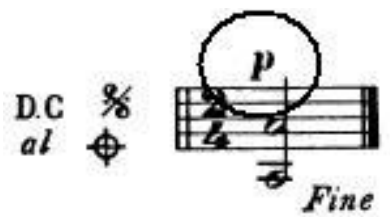

Ex.17 - Indicação de dinâmica $(p)$ ao final (c.38) do Prelúdio $n^{\circ} 3$ de Villa-Lobos.

É interessante notar que as indicações de $m f$ (início da peça), $f$ (início da Seção B) e $p$ (final da peça), se observadas de forma dialógica com o que já foi exposto em relação ao plano formal (aspectos gerais de indicações agógicas e estruturação harmônica), podem reforçar a concepção sonora já discutida: acréscimo de tensão-expectativa ao longo da Seção $A$ até chegar ao segmento de transição com a Seção B (V); posteriormente, ocorre dissipação de energia até o final da peça (Ex.18):

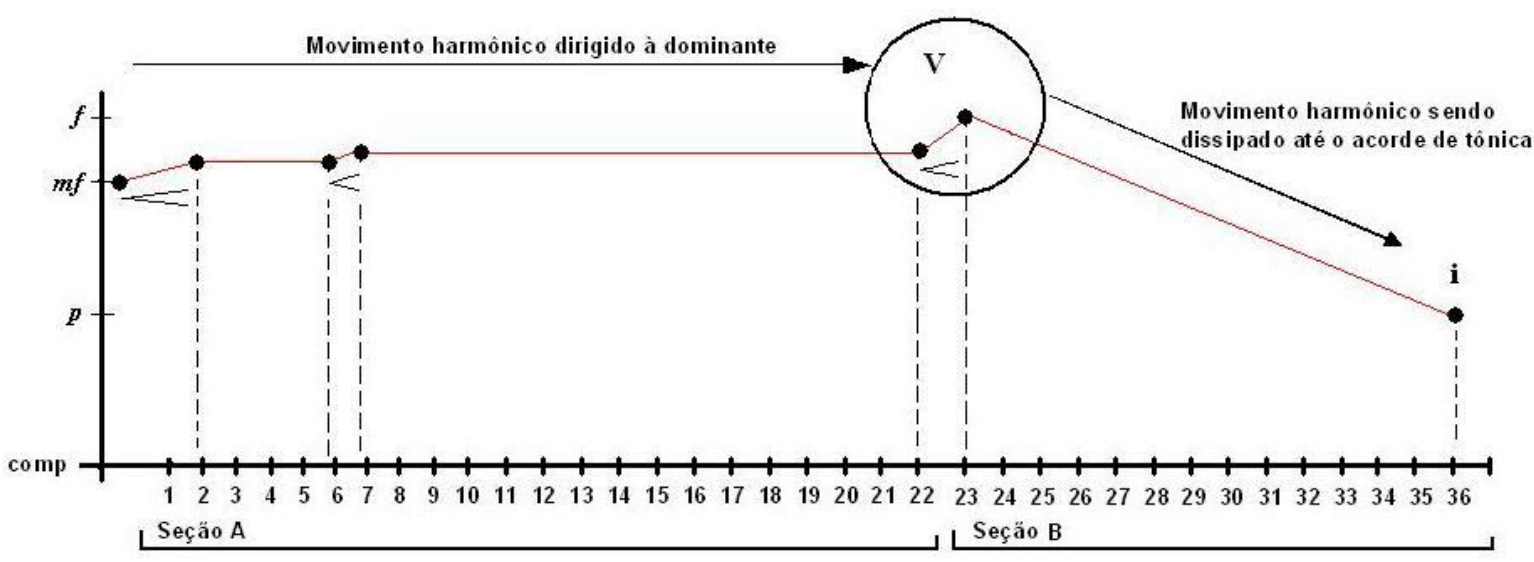

Ex.18 - Gráfico da flutuação dinâmica no Prelúdio $n^{\circ} 3$ de Villa-Lobos. Eixo vertical indica a variabilidade de intensidade; o eixo horizontal indica os compassos.

O gráfico reforça a convergência dos planos harmônico e dinâmico. Além disso, no início da Seção B (c.23) a indicação de Molto adagio (dolorido) mostra ainda que neste ponto a dramaticidade de toda peça é acentuada.

É importante ressaltar que a performance não deve refletir a dureza do gráfico de dinâmica apresentado no Ex.18, mas sim, contornos imagéticos mais flexibilizados, "arredondados" (Ex.19). Uma imagem mais aproximada poderia ser assim visualizada: 


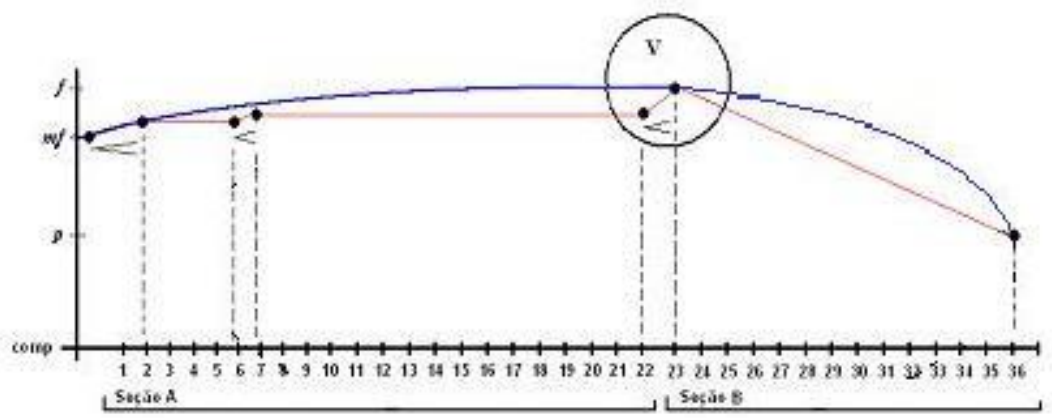

Ex.19 - Gráfico da flutuação dinâmica no Prelúdio no 3 de Villa-Lobos a partir da perspectiva de um arco dinâmico.

Contudo, nota-se que os gráficos de dinâmica apresentados, bem como as considerações feitas sobre este parâmetro e sua inter-relação com o movimento harmônico, apresentam informações interessantes para o intérprete no que se refere ao fluxo de energia e sua visualização através do contorno da peça como um todo. Um aspecto importante que o intérprete pode considerar durante 0 processo de compreensão do Prelúdio $n^{\circ} 3$, é que o arco dinâmico apresentado no último gráfico mostra um pequeno crescimento no panorama dinâmico que se estende do c.1-22 (Seção A). Após chegar ao ápice no c.23, começa um decrescimento que se estende do c.23-36 (Seção B), finalizando a peça num $p$.

\subsection{Agrupamentos (groupings)}

Os gráficos abaixo apresentam uma característica peculiar na Seção A. Em decorrência da alternância de compassos e da ocorrência de sobreposições (phrase overlap; sub-phrase overlap $)^{13}$, preferimos aqui adotar gráficos que tratem dos agrupamentos frasais a partir do conceito de grouping, apresentado por LERDAHL e JACKENDOFF (1983) ${ }^{14}$. Isso ocorre pela dificuldade de se trabalhar com a técnica de redução rítmica preconizada por RINK (2007), pelas razões mencionadas acima.

A Seção $A^{15}$ inicia com uma frase que se estende do c.1-5, chegando ao acorde de $\mathrm{V}^{7}$ (Ex.20): 


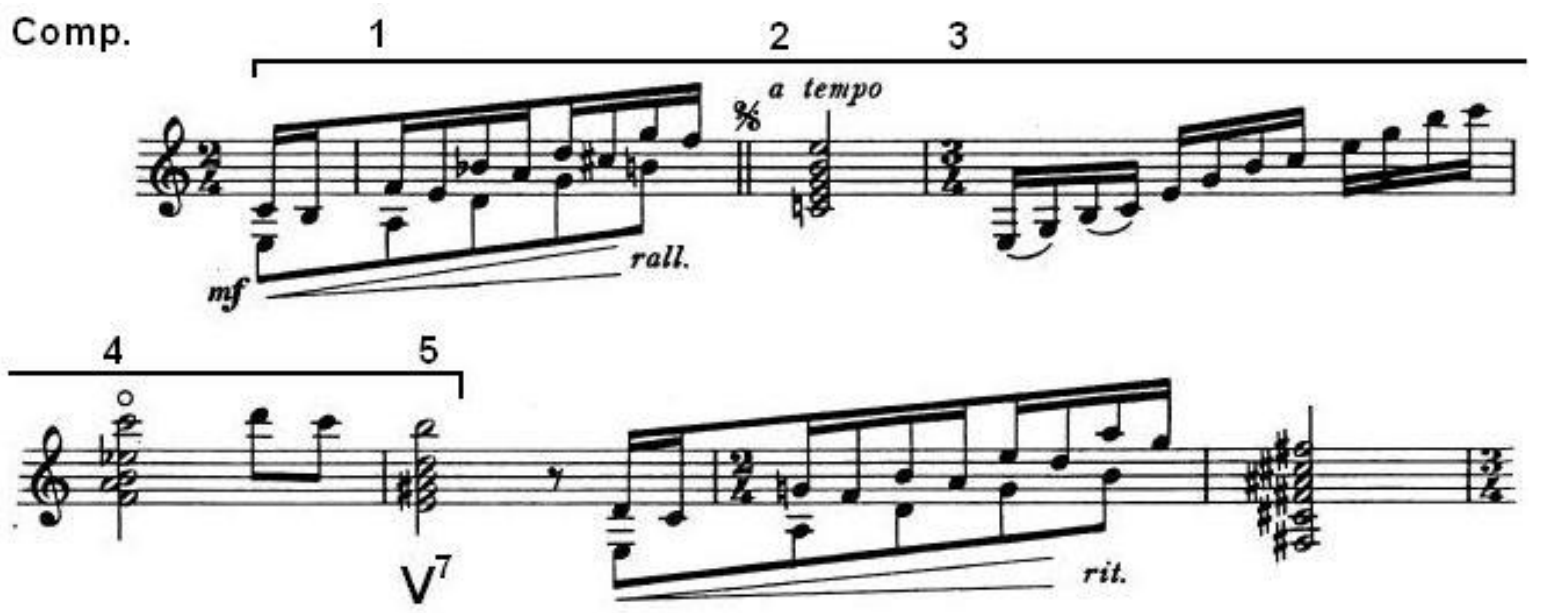

Ex.20 - Segmento frasal que inicia o Prelúdio no 3 (c.1-5) de Villa-Lobos. Movimento ao V7.

Redução da superfície para visualização dos segmentos frasais (Ex.21):

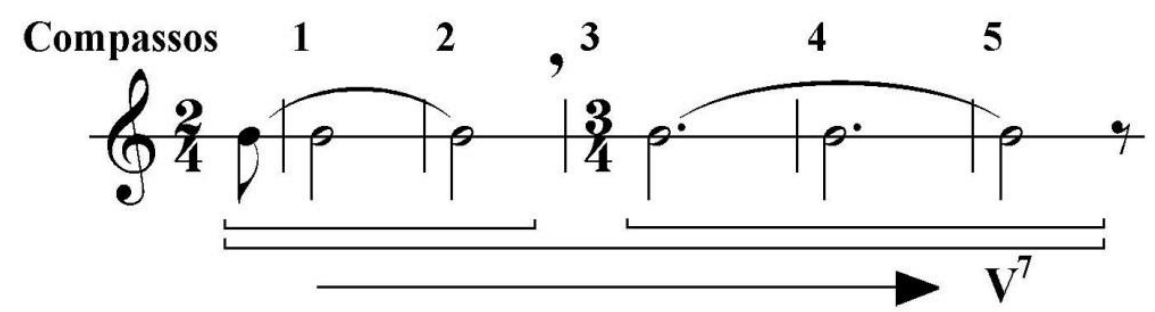

Ex.21 - Redução da superfície dos c.1-5 e visualização dos agrupamentos (groupings) frasais do Prelúdio $n^{\circ} 3$ de Heitor Villa-Lobos.

As ligaduras de prolongamento são utilizadas para que se tenha uma observação mais clara dos compassos que estão relacionados dentro da estrutura frasal. Estas, por sua vez, são explicitadas pelos colchetes que identificam dois níveis estruturais, ou seja, os menores colchetes se referem a unidades interpretadas como semi-frases, as maiores, frases. É importante salientar que essas descrições pretendem apresentar a ideia de agrupamentos (groupings), ou seja, uma maneira de tornar a peça inteligível dentro das possibilidades de nossa percepção.

A segunda frase (c.6-9) conecta o segmento motívico já apresentado nos c.1-4 com a sub-seção A" (c.9-13 - ver exemplo 24) elaborada com o já mencionado paralelismo de acordes (paralelism) (Ex.22): 

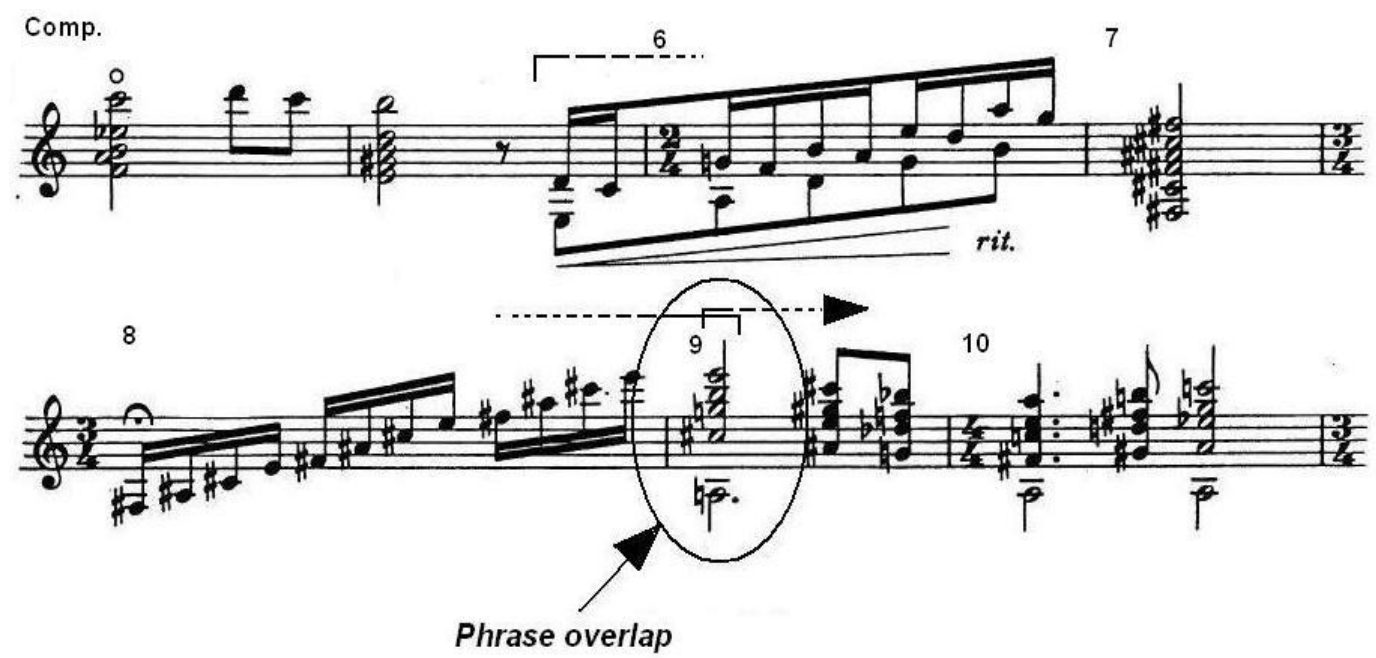

Ex.22 - Phrase overlap conectando a sub-seção A' com a sub-seção A" (c.9) no Prelúdio no 3 (c.410) de Heitor Villa-Lobos.

Vejamos o Ex.23:

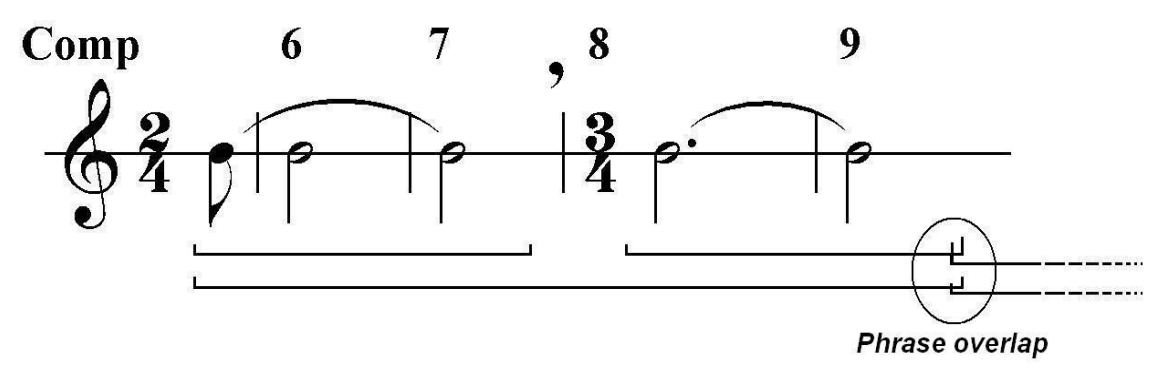

Ex.23 - Segunda semi-frase da sub-seção A' (c.6-7) e interseção com o início da sub-seção A" (c.9) do Prelúdio no 3 de Heitor Villa-Lobos.

A interpretação de phrase overlap leva em consideração o fato de que o fluxo do discurso musical é ininterrupto, embora a mudança de caráter através da articulação dos materiais que ocorre no c.9. Dessa maneira, o acorde de Dó\# meio-diminuto sobre o pedal de Lá (5 $5^{\text {a }}$ corda solta), circulado no Ex.23, faz parte tanto da segunda semi-frase da sub-seção A (Ex.24, c.8-9), quanto da primeira sub-frase contida no Ex.24.

Abaixo, a sub-seção correspondente aos c.9-13 (Ex.24): 


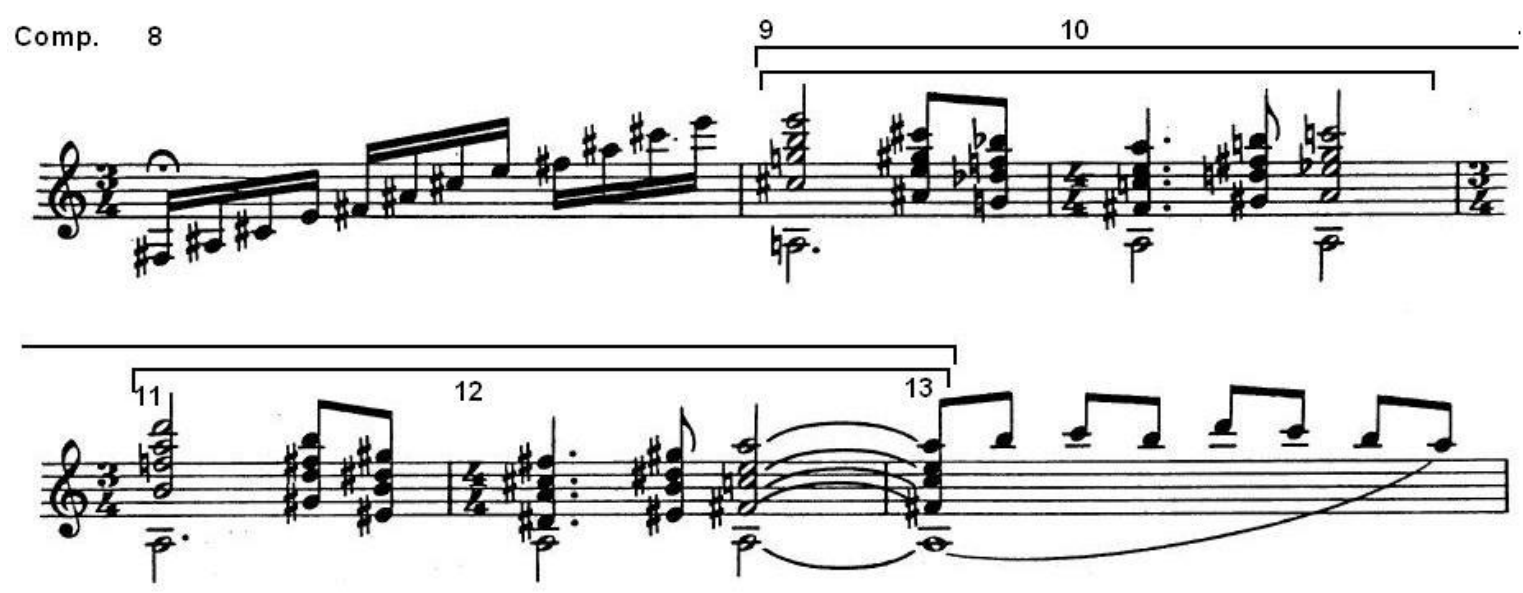

Ex.24 - Superfície correspondente à sub-seção A" (c.9-13) do Prelúdio no 3 (c.8-13) de Heitor VillaLobos.

Simplificação da superfície (Ex.25):

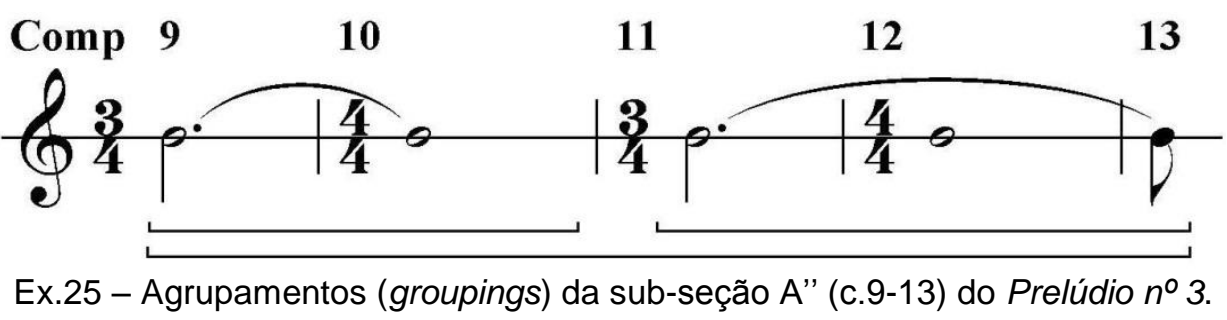

É interessante notar que os acordes paralelos estão relacionados ao material rítmico utilizado no c.4 (Ex.26),

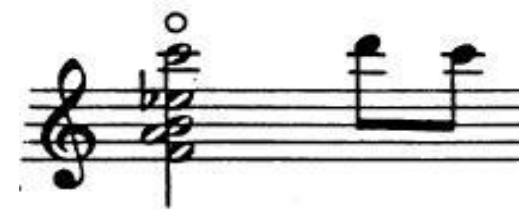

Ex.26 - Material motívico utilizado no c.4 do Prelúdio nº 3 de Heitor Villa-Lobos.

assim como conferem um caráter estático ao trecho, reforçado através da utilização dos acordes fora de uma perspectiva tonal tradicional. Esse caráter confere um contraste em relação a tudo o que ocorreu na peça até se chegar ao c.9. Os materiais mais utilizados anteriormente possuem um papel de geradores de ímpeto. Os movimentos ascendentes da linha melódica parecem dirigir-se aos poucos até o c.9, onde se estabelece um momento de estabilidade pelas características já mencionadas sobre o trecho.

Nos c.13-16 (Ex.27) surge uma melodia de caráter lírico. Esta, por sua vez, necessita de uma articulação bastante atenciosa por parte do performer. 

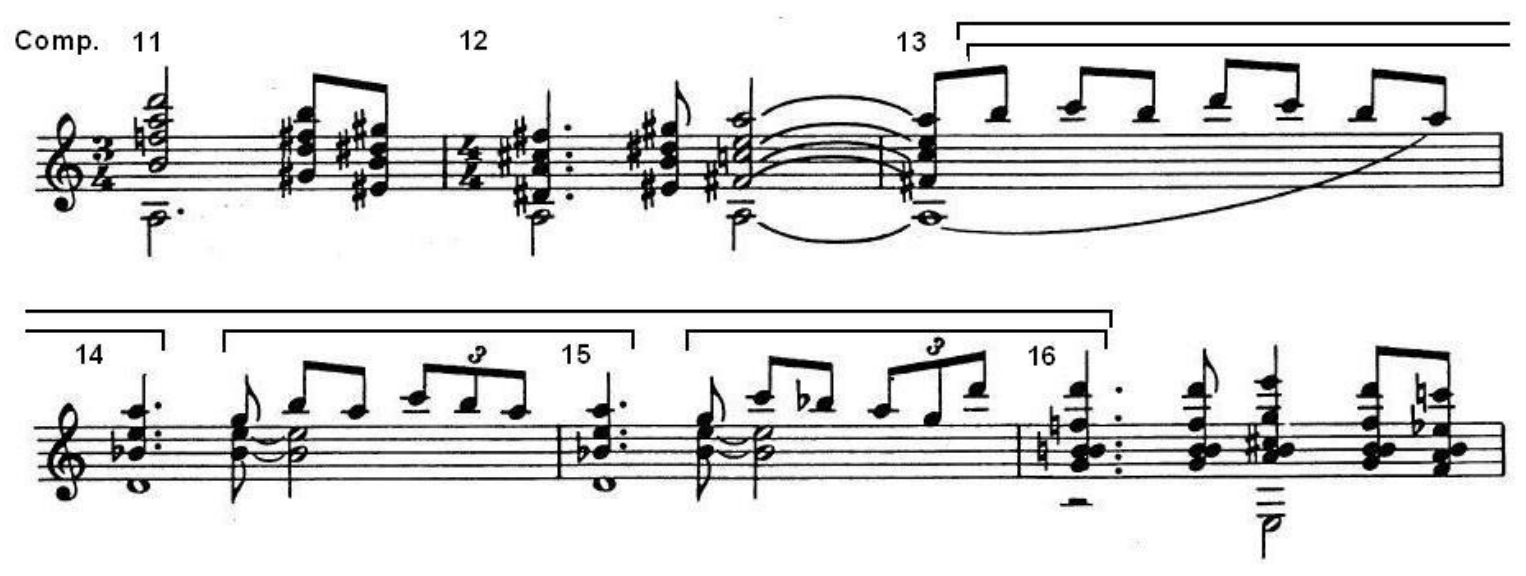

Ex.27 - Visualização da superfície da sub-seção A"” (c.13-16) do Prelúdio no 3 (c.11-16) de Heitor Villa-Lobos.

Nota-se que ao final da melodia (c.15) pode-se interpretar como sendo uma phrase overlap, embora de caráter menos convincente. Aqui, há a retomada aproximada da tessitura alcançada no c.9 (Ex.24) através do salto ascendente de $5^{\text {a }}$ justa entre as notas Sol 3 e Ré 4 (Ex.28):

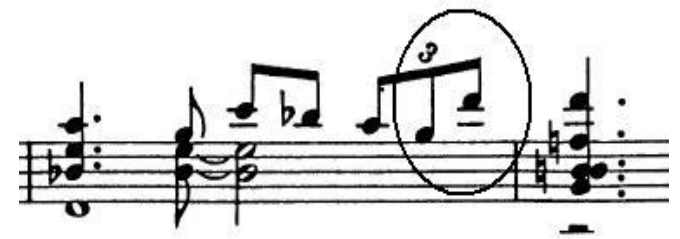

Ex.28 - Phrase overlap correspondente aos c.15-16 do Prelúdio no 3 articulada por salto de $5^{\text {a }}$ ascendente.

Pode-se visualizar o segmento todo (c.13-16) da seguinte maneira (Ex.29):

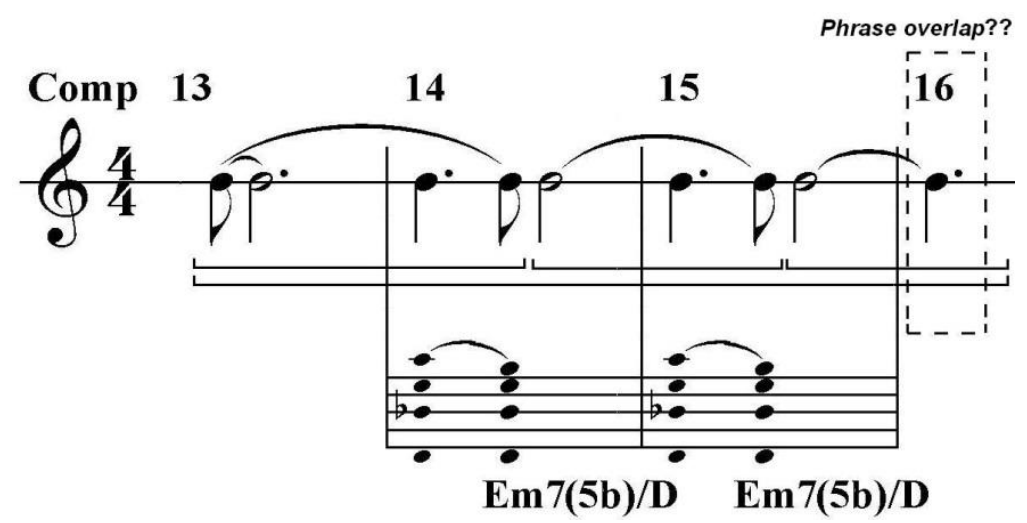

Ex.29 - Agrupamentos (groupings) da primeira metade da sub-seção A"' (c.13-16) do Prelúdio no 3 de Heitor Villa-Lobos.

A figura (Ex.29) ressalta o caráter breve da melodia que é apresentada nos c.1316. Neste momento da Seção A, o intérprete deve ter em mente de que se trata do 
único momento lírico, estabelecendo contraste com os demais segmentos da seção.

Conforme mencionado acima, sobre a retomada da tessitura alcançada no c.9, assim como do ímpeto da Seção A, o trecho no Ex.30 (c.16-22) afirma o ponto culminante da peça: a chegada definitiva à harmonia de dominante $\left(\mathrm{V}^{7}\right)$. Tal chegada reutiliza material rítmico apresentado no c.10, bem como o paralelismo de acordes, finalizando a seção A:

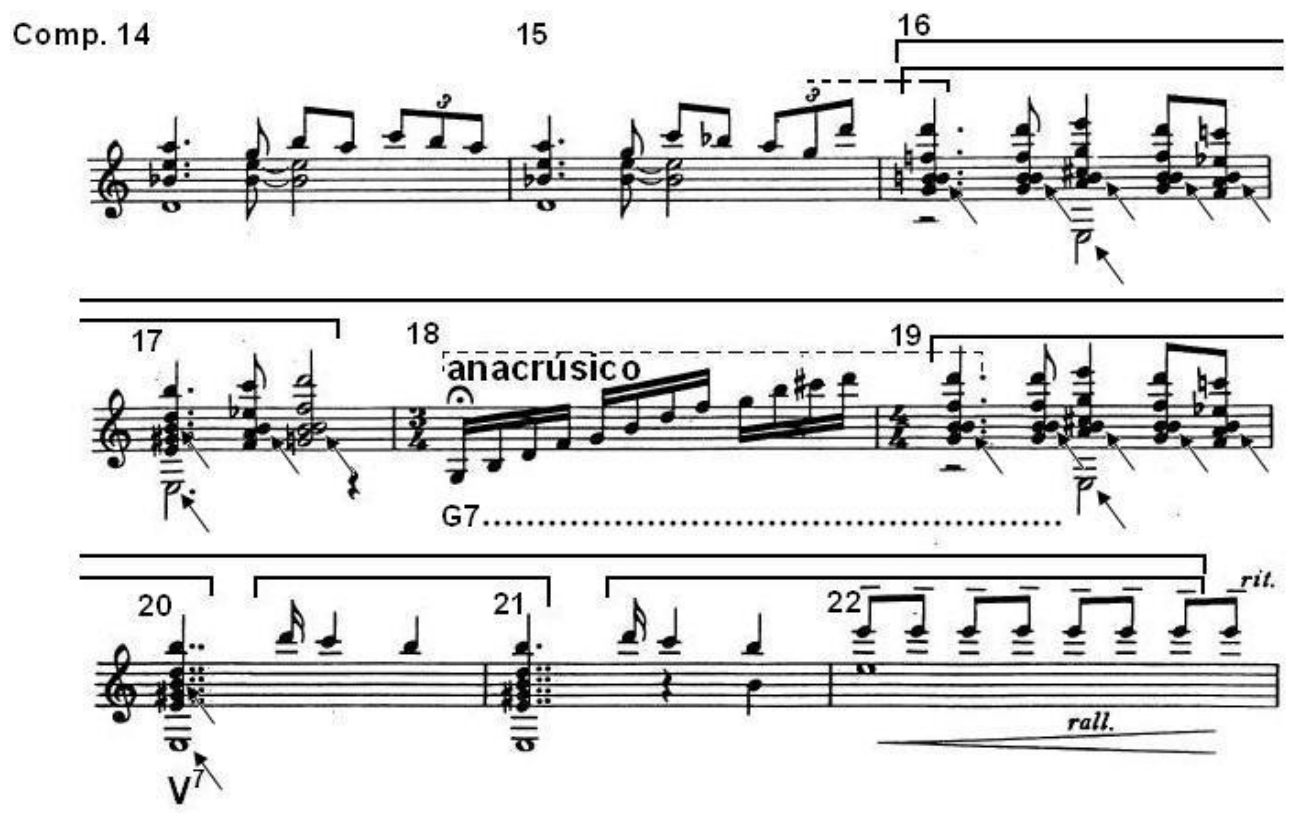

Ex.30 - Finalização da Seção A do Prelúdio no 3 (c.14-22): segunda metade da sub-seção A"' (c.16-22).

Nota-se que no c.18 reaparece um material apresentado anteriormente que possuía o caráter de gerador de ímpeto. Dentro deste contexto, o intérprete pode considerá-lo um prolongamento do acorde de Sol maior com sétima menor (G7), bem como material que é utilizado para retomar rapidamente a tessitura alcançada no c.9, possuindo um caráter anacrúsico (upbeat).

Neste trecho (c.16-22) se reflete a convergência de aspectos da harmonia na composição para violão de Villa-Lobos: as funções estruturais das cordas soltas como notas pedais (ver as setas indicativas no ex.30) que geram o direcionamento a um centro tonal (GOLDSPIEL, 2000, p.8). Nota-se que, apesar da utilização de alguns acordes de sétima de dominante, o pedal caracterizado pela nota Mi (6 ${ }^{\underline{a}}$ corda solta) dirige toda a expectativa para a confirmação da harmonia de dominante $\left(\mathrm{V}^{7}\right)$ no c.20. Outra corda solta funcionando como nota pedal é a nota Si 2 ( $2^{-}$corda solta). Este pedal aparece no interior de todos os acordes do trecho, antecipando a chegada da nota que compõe a $5^{\text {a }}$ justa do acorde de dominante $\left(V^{7}\right)$, estabelecido no c.20 (Ver as setas indicativas no Ex.30). 
A estruturação frasal do trecho (Ex.31):

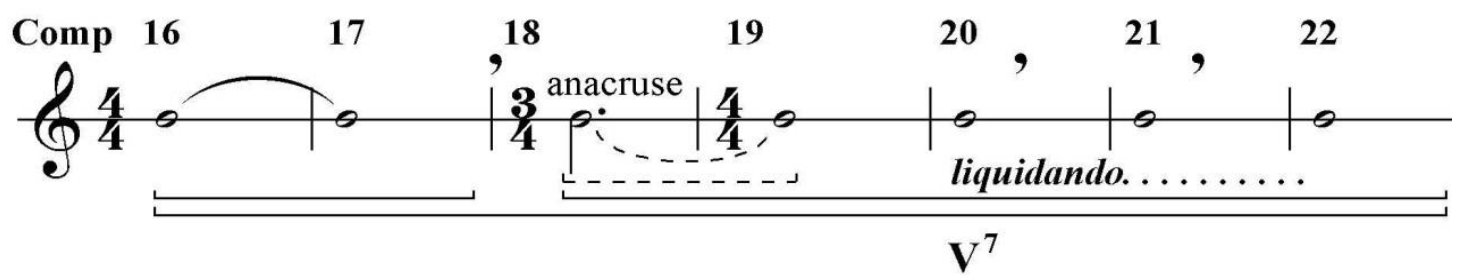

Ex.31 - Visualização dos agrupamentos (groupings) frasais da segunda metade da sub-seção A"' (c.16-22) do Prelúdio no 3.

Abaixo (Ex.32), pode-se visualizar como está organizada a Seção A a partir da análise dos segmentos acima:
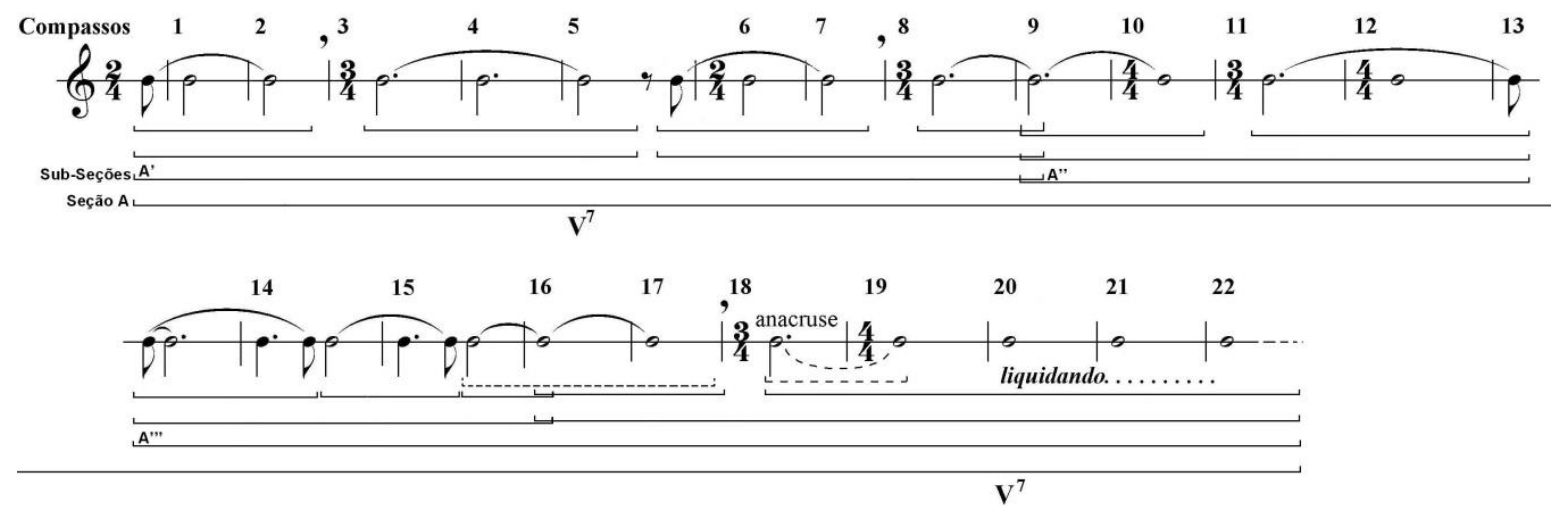

Ex.32 - Visão panorâmica da articulação da Seção A (c.1-22) e suas sub-seções A' (c.1-9), A" (c.9-13) e A"' (c.14-22).

A Seção B é menos complexa em decorrência do caráter quase-invariável de seus agrupamentos frasais. A sensação harmônica é de um claro direcionamento que vai do $\mathrm{V}$ ao i (Ex.33): 


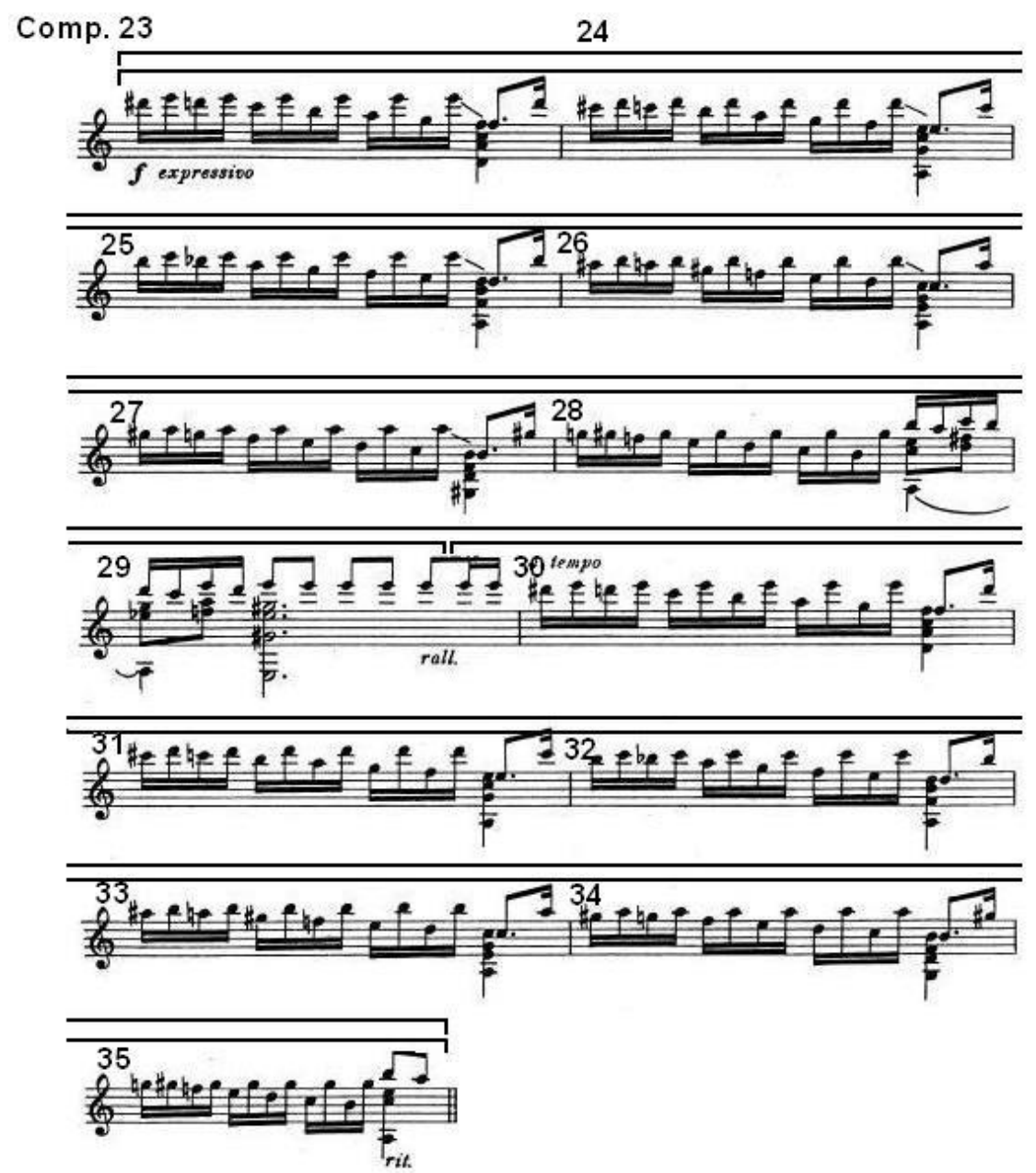

Ex.33 - Superfície da Seção B (c.23-35) do Prelúdio no 3 de Heitor Villa-Lobos. Colchete mais abaixo indica o fracionamento em duas sub-seções, ou seja, sub-seção B' (c.23-29) e sub-seção B" (c.30-35).

É importante que o intérprete tenha sempre em mente a importância de cada frase como uma entidade a ser articulada em seu próprio contexto (colchetes menores, primeira linha), assim como deve considerar cada uma como parte integrante dentro da articulação da sub-seção e da seção como um todo.

Ao observar detalhadamente o final da Sub-seção B' (c.28) nota-se, mais uma vez, uma phrase overlap, assim como no caso do c.19 (Ex.28; Ex.29). Dessa maneira, é estabelecida a continuidade do fluxo no sentido de retomar a tessitura alcançada no c.23 (início da Seção B). Após, repete-se, praticamente sem alterações, a Sub-seção B' (Ex.34): 

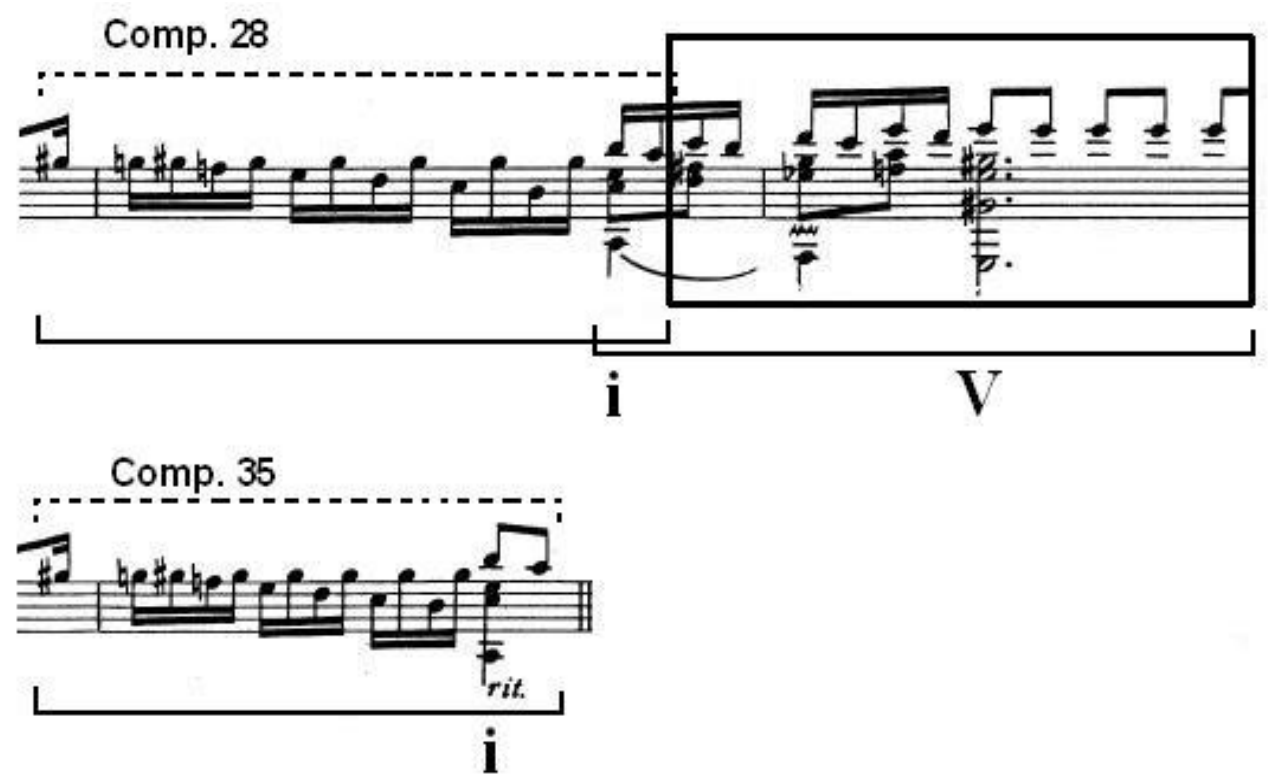

Ex.34 - Trechos referentes aos finais das sub-seções B' (c.28) sub-seção B" (c.35) do Prelúdio no 3 de Villa-Lobos.

Abaixo (Ex.35), os agrupamentos (groupings):

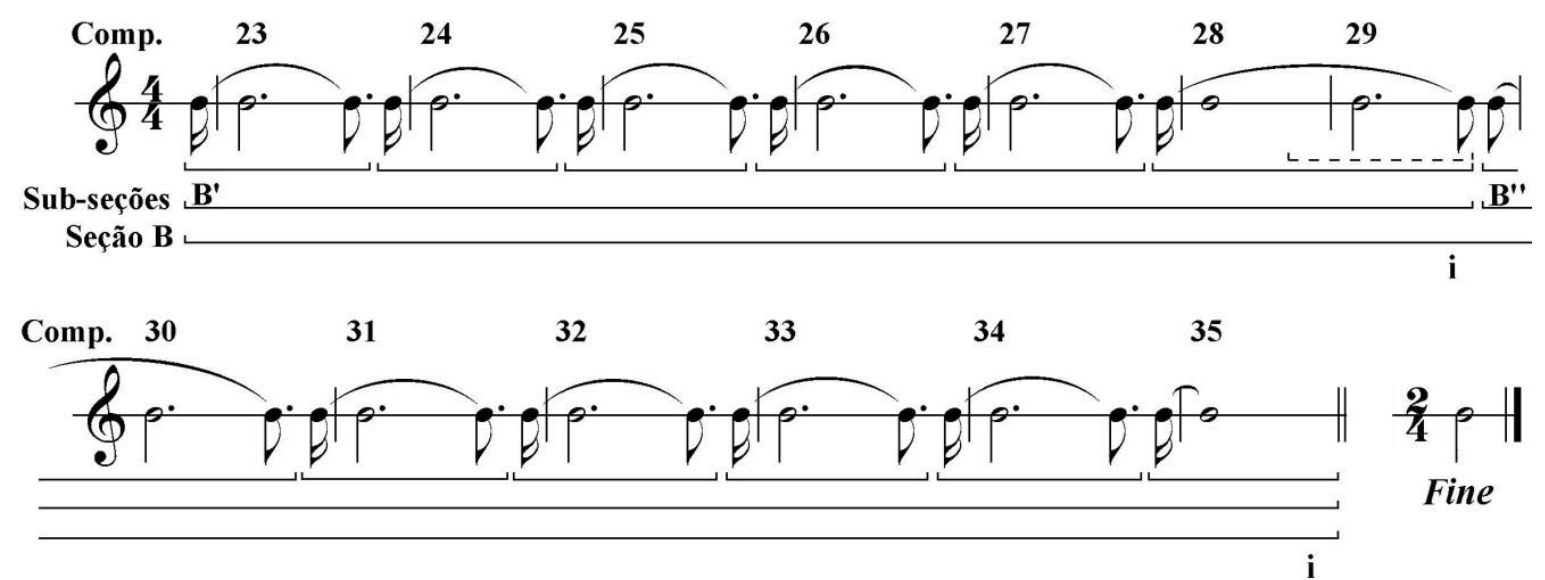

Ex.35 - Visualização dos agrupamentos (groupings) correspondentes à Seção B (c.23-35), subseções B' (c.23-29) e B" (c.30-35), bem como segmentos frasais menores do Prelúdio no 3.

\section{5 - Conclusões}

Acreditamos que o intérprete, no momento em que começa a construção de sua interpretação, ingressa em um processo de aprendizagem. Além disso, considerando o conhecimento como sendo produzido através da compreensão relacional, parte-se da perspectiva de que o próprio processo de aprendizagem se torna amplo e complexo. Portanto, na medida em que o intérprete parte da ideia de que seu aprendizado não é adquirido somente através da intuição, mas 
MEDEIROS, D. R. Prelúdio no 3... Villa-Lobos... processo interpretativo. Per Musi, Belo Horizonte, n.31, 2015, p.189-214.

também da relação desta com a visão contextual (perspectivas histórica, cultural, estética, etc), tem-se uma dimensão importante do conhecimento.

Embora o processo analítico aqui tenha lidado apenas com aspectos estéticoestilísticos relacionados à obra para violão solo de Heitor Villa-Lobos, acredita-se que se apresentam de forma importante dentro do processo reflexivo. Sendo o Prelúdio $n^{\circ} 3$ uma peça que dialoga com linguagens estéticas até certo ponto distintas em cada Seção, os parâmetros trabalhados na parte de contextualização (características harmônicas e ornamentação) trazem uma perspectiva importante em termos de compreensão. As características harmônicas destacadas trouxeram informações importantes, principalmente para a concepção adotada na articulação da Seção A. As informações referentes aos portamentos indicados na partitura também apontam para um importante elemento da linguagem estética villalobiana, o qual deve ser no mínimo considerado no processo interpretativo-reflexivo.

No plano formal, por exemplo, as considerações acerca das indicações de ralentando (rall), ritenuto (rit), dinâmica, tenutos - no segmento de transição entre as Seções A e B -, bem como as considerações sobre o plano harmônico da Seção A (largo direcionamento ao V), quando relacionadas entre si, chamam atenção no sentido da quantidade de informações que podem proporcionar inteligibilidade na concepção interpretativa, principalmente em se tratando da articulação da peça do ponto de vista panorâmico. Além disso, o diálogo entre as informações obtidas através do próprio plano formal e do gráfico de dinâmica também apresentam uma perspectiva panorâmica na concepção sonora da peça.

Os agrupamentos apresentam um olhar mais aprofundado em termos de articulação de unidades de sentido, seja em planos mais localizados ou mais panorâmicos. Em decorrência disso, tem-se uma imagem de como cada Seção pode ser articulada, por exemplo, através da ideia de sub-seções. Dessa forma, tem-se uma visão mais focalizada em termos de estruturação e de como podem ser articuladas cada Seção.

Por fim, a análise aqui apresentada pretende mostrar-se como somente uma possibilidade, dentre tantas outras, em termos de processos de interpretação.

\section{Referências}

DUDEQUE, Norton Eloy. História do Violão. Curitiba: Ed. da Universidade Federal do Paraná, 1994.

GOLDSPIEL, Alan. A new look at musical structure and the guitar in the music of Villa-Lobos. Soundboard Magazine, n.2, p.7-13, 2000.

GREEN, Douglass. Form in tonal music: an introduction to analysis. New York: Holt, Rinehart and Winston, 1979.

HILL, Peter. From score to sound. In: Musical Performance. A Guide to Understanding. Cambridge: CUP, p.129-143, 2002.

JACKENDOFF, Ray; LERDAHL, Fred. A generative theory of tonal music. London: MIT Press, 1983. 
MEDEIROS, D. R. Prelúdio no 3... Villa-Lobos... processo interpretativo. Per Musi, Belo Horizonte, n.31, 2015, p.189-214.

JAFFEE, Michael. Harmony in the solo guitar music of Heitor Villa-Lobos. Guitar Review. New York, n.29, p.18-22, 1966.

PRADA, Teresinha. Violão: de Villa-Lobos a Leo Brouwer. São Paulo: Terceira Margem, 2008.

RINK, John. Análise e (ou?) performance. Cognição \& Artes Musicais/Cognition \& Musical Arts. v.2, n.1, p.25-43, 2007.

SANTOS, Turíbio. Heitor Villa-Lobos e o violão. Rio de Janeiro: Museu Villa-Lobos, 1975.

VILLA-LOBOS, Heitor. Guitar Etudes. Paris: Max Eschig, 1953. Violão solo.

VILLA-LOBOS, Heitor. Cinq Préludes. Paris: Max Eschig, 1954. Violão solo.

WALLS, Peter. Historical Performance and the modern performer. In: Musical Performance. A Guide to Understanding. Cambridge: CUP, p.17-34, 2002.

\title{
Leitura recomendada
}

DOĞANTAN, Mine. Upbeat. In: New Grove Dictionary of Music and Musicians. New York: Oxford Press, Inc. 2001.

FALLOWS, David. Tenuto. In: New Grove Dictionary of Music and Musicians. New York: Oxford

Press, Inc. 2001.

ROTHSTEIN, William Nathan. Phrase rhythm in tonal music. New York: Schirmer, 1989.

\begin{abstract}
Notas
${ }^{1}$ Não trataremos aqui de questões extra-musicais ligadas ao caráter programático das peças, uma vez que a potencialidade de investigação acerca das relações entre algumas estruturas musicais e suas ligações com os "discursos" contidos nos subtítulos, demandaria um estudo mais pormenorizado a partir desta perspectiva.

${ }^{2}$ Charlatão; impostor; trapaceiro.

${ }^{3}$ Seja em nível de formação de repertório do ponto de vista estético e/ou técnico-violonístico.

4 Segundo DUDEQUE (1994), "Turíbio é um dos maiores divulgadores da obra do grande compositor brasileiro e hoje dirige o Museu Villa-Lobos" (DUDEQUE, 1994, p.103).

${ }^{5}$ As considerações gerais a respeito da obra para violão de Heitor Villa-Lobos estão colocadas de forma bastante genérica na Introdução deste trabalho. Dessa forma, reiteramos que para a construção de uma concepção mais adequada, deve-se fazer um levantamento maior do que foi apresentado.

6 Esta análise não explorará um aspecto muito considerado como primário na tradição do ensino do violão: a digitação. Segundo HILL (2002), a digitação deve estar de acordo com o fim que se objetiva dentro da construção de uma concepção musical (HILL, 2002, p.132), portanto, um processo subsequente. Sendo assim, consideramos a elaboração de uma concepção da obra como um processo primário, anterior à execução (resultado físico) (HILL., 2002, p.133).

7 Ver a lista de questões básicas apresentada por WALLS (2002, p.23). Tal lista oferece um exemplo de como o intérprete pode estabelecer parâmetros para uma compreensão contextualizada da partitura.

${ }^{8} \mathrm{~A}$ nosso ver, um exemplo das entrelinhas que HILL (2002) observa.

9 Para maiores considerações, ver o verbete Tenuto (FALLOWS, 2001) no New Grove Dictionary of Music and Musicians (2001).

10 Para maiores considerações, ver o verbete Upbeat (DOĞANTAN, 2001) no New Grove Dictionary of Music and Musicians (2001).

11 Para a especificação da tessitura, levou-se em consideração a característica do violão como instrumento transpositor de uma oitava abaixo. Portanto, o Mi4, por exemplo, refere-se à grafia para violão.

${ }^{13}$ A interpretação de sobreposição de frases ou semi-frases parte do conceito de phrase overlap e subphrase overlap, contido em Phrase rhythm in tonal music (1989), de William Nathan Rothstein (p.44-51).
\end{abstract}


${ }^{14}$ Do ponto de vista psicológico, agrupamento de uma superfície musical é uma analogia auditiva do particionamento do campo visual em objetos, partes de objetos e partes de partes de objetos. Mais que qualquer outro componente da gramática musical, o componente de agrupamento parece ser de óbvio interesse psicológico, em que a gramática que descreve a estrutura dos agrupamentos parece consistir amplamente de condições gerais para a percepção de padrões auditivos que têm aplicação muito mais ampla que para a música sozinha. Além disso, as regras para agrupamentos parecem ser do tipo idioma-independente - isto é, um ouvinte necessita conhecer relativamente pouco sobre um idioma musical a fim de atribuir estruturas de agrupamentos às peças naquele idioma" (JACKENDOFF; LERDAHL, 1983, p.36).

15 É importante salientar que a Seção A sugere um caráter evocativo, como se fosse uma grande preparação impressionista à Seção $\mathrm{B}$, uma homenagem a Bach.

Daniel Ribeiro Medeiros é Bacharel em Música - Habilitação em Violão pela Universidade Federal de Pelotas (2004) e Mestre em Música (Interpretação/Processos Criativos: Teoria, Criação Musical e Estética) pela Universidade federal do Paraná (2010), sob orientação do Prof. Dr. Norton Dudeque. Em suas pesquisas, tem abordado temáticas relacionadas a Teoria, Análise e Historiografia Musical. São trabalhos que envolvem investigações no âmbito da chamada música "culta" e música popular, tais como rock, música latino-americana (Rio Grande do Sul, Uruguai e Argentina) e música de concerto. Orientado pela profa. Dra. Isabel Porto Nogueira, realiza doutorado no Programa de Pós-Graduação em Memória Social e Patrimônio Cultural da Uiniversidade Federal de Pelotas, cujo projeto envolve o estudo da música popular (rock) a partir de enfoque interdisciplinar ligado às conformações sociais e identidades (Antropologia Social, Memória e Identidade, Etnomusicologia, História Oral). 